\title{
Electromagnetic Interference (EMI): Measurement and Reduction Techniques
}

\author{
PHALGUNI MATHUR ${ }^{1}$ and SUJITH RAMAN (1) ${ }^{1,2}$ \\ 1.-Department of E \& I, Bharathiar University (BU), Coimbatore, Tamil Nadu, India. 2.-e-mail: \\ sujithrpkd@gmail.com
}

Electromagnetic interference (EMI) is one of the biggest challenges faced during the production of any electronic device. The effect on the performance of the instrument due to these inevitable interferences must be carefully measured to understand and quantify the electromagnetic compatibility (EMC) of the instrument under test. If the EMI profile of the system does not meet the accepted standards, then it becomes necessary to take measures to reduce the influence of these unwanted interferences so that the equipment can be used in the real world. Unfortunately, research and studies on EMI and EMC have not received their due attention from the scientific community. Moreover, the literature available for this area of research is scattered where different sources provide information on one or more (but not all) aspects of EMI/EMC while ignoring the others. With the objective of encompassing this extremely significant area of research in its entirety, this review presents both EMI measurement techniques and EMI reduction techniques in detail. EMI measurement techniques are presented under two sections that deal with emission testing and immunity testing, respectively. Herein, EMI reduction techniques are presented under four sections, where electromagnetic shielding has been given special attention under which various methods used by the scientific community to measure the shielding effectiveness of a material or microwave absorber and its application in EMI reduction are illustrated. This is followed by EMI filters, circuit topology modification and spread spectrum. This review can help students and young scientists in this area to get an idea of the ways to conduct EMI tests as well as the ways that can be employed to reduce the EMI of the system, depending on the application.

Key words: electromagnetic interference (EMI), EMI testing, shielding effectiveness, microwave absorber

\section{INTRODUCTION}

Most of the present day electronic applications make use of miniaturized compact devices that enclose hundreds and thousands of passive and/or active components to perform multiple operations simultaneously. Although arranging such a large number of components on a device with dimensions not more than a few centimeters is a huge challenge

(Received October 11, 2019; accepted January 28, 2020; published online February 18, 2020) in itself, the biggest hurdle that any electronic hardware engineer or manufacturer faces is to develop high-speed multifunctional devices that are not only compact but are also electromagnetically compatible. Electromagnetic compatibility (EMC) is a measure of immunity that the device possesses against the undesired interferences present in its electromagnetic environment. ${ }^{1}$ Moreover, apart from being susceptible to these spurious noises, an electronic device is capable of generating or radiating these noise signals in the environment that can hamper the working of nearby electronic systems. In order to estimate a device's immunity 
and the amount of interference it can potentially generate in its environment, the electromagnetic interference (EMI) associated with it must be measured. EMI leads to the obstruction or degradation of the performance of any electrical equipment by inducing unwanted currents and voltages in its circuitry. ${ }^{2}$ Such interferences can prove to be fatal for the system itself and are usually due to a number of reasons that can be categorized as follows:

A. Natural Sources Cosmic rays, solar flares, snow, storms, rain, and thunder are a few examples of the natural phenomena that contribute to EMI generation in electronic circuits. The interference arising due to these sources is one of the main causes of EMI in radio systems. ${ }^{3}$ Systems involved in space applications, aerospace applications, ground-based radar, radio astronomy and telecommunication applications are most affected due to these sources of interference. Since man has no control over these events, extra care must be taken while designing the electronic circuitry.

B. Man Made Sources This category can be further divided into two sub-categories as follows:

(a) Involuntary Sources The constituent components of a circuit can interfere with the working of another component in the circuit or other nearby devices through conduction (via wires and cables) or radiation (via electromagnetic fields). Some common sources of involuntary man-made interference are mobile phones, laptops, radios, medical equipment, X-ray machines, microwave ovens, power cables, ignition systems, air conditioners, hair dryers, automobile vehicles, thermostats and many more. ${ }^{4}$ Almost all electronic systems experience as well as cause the interference due to these sources.

(b) Voluntary Sources In hostile situations as that of a war, radars are made to emit high power to cause fatal interference within enemy radars and communication systems in order to neutralize them. ${ }^{3}$

Efforts to mitigate the effects of EMI on electronic systems began during the Second World War. Until the 1960 s, ways to reduce EMI were solely concerned with defence applications. With the rapid growth of computer technology during the 1970s and $1980 \mathrm{~s}$, the paralyzing effects of EMI were encountered in civilian applications after which it was taken very seriously by the scientific and engineering communities. ${ }^{5}$ All modern day electronic devices are thus required to be well shielded in order to avoid harmful effects of EMI as well as to block any spurious radiation or harmful coupling that might contribute to involuntary interferences.

The production flow of an electronic device involves numerous steps, as shown in Fig. 1, starting from the initial investigation and research to the mass production. During the compliance testing phase, the device is required to clear several EMI tests that are based on a number of international and national standards set by individual countries. ${ }^{6-8}$ These tests are quite expensive; therefore, if the product fails at this stage then the entire cycle must be repeated which leads to an unprecedented increase in the cost of production. However, if economical pre-compliance EMI testing is performed at each step of product development, then the probability of failing the aforementioned tests decreases drastically. Also, it is easier and more affordable to troubleshoot and solve the issues related to EMI if they are encountered in the early stages of product development. This highlights the importance of EMI measurements in the early phases of any electronic device manufacturing. The type of test and the standard to be met vary according to the intended application of the product.

In case of significant EMI in the circuitry, several methods can be employed to enhance the immunity of the system such as enhancing the shielding effectiveness using various conductive materials or microwave absorbers, ${ }^{9,10}$ making use of EMI filters, ${ }^{11,12}$ optimizing the layout of the circuit ${ }^{13}$ etc.

Although EMI/EMC plays a very important role in electronic engineering, research and development in this area is still insufficient when compared to other aspects of electronic engineering and product development. Moreover, the literature available for this area is spread out. Most sources do not discuss EMI/EMC in totality thereby making it difficult for young researchers to fully understand the structure of this field. In this review, efforts have been made to address this problem by comprehensively discussing the measurement techniques along with ways to mitigate the EMI associated with an electronic system. This paper is organized into two sections. The first section focuses on EMI measurement techniques where EMI emission and immunity testing methods are discussed elaborately. The second section deals with EMI reduction techniques where electromagnetic shielding, EMI filters, circuit topology modification and spread spectrum are discussed.

\section{EMI MEASUREMENT TECHNIQUES}

EMI testing can be done either as compliance testing (by strictly following the instructions mentioned in the authorized standards) or pre-compliance testing (developing newer in-house techniques). The test beds of all pre-compliance setups must imitate the compliance test setup as closely as possible in terms of hardware, software 


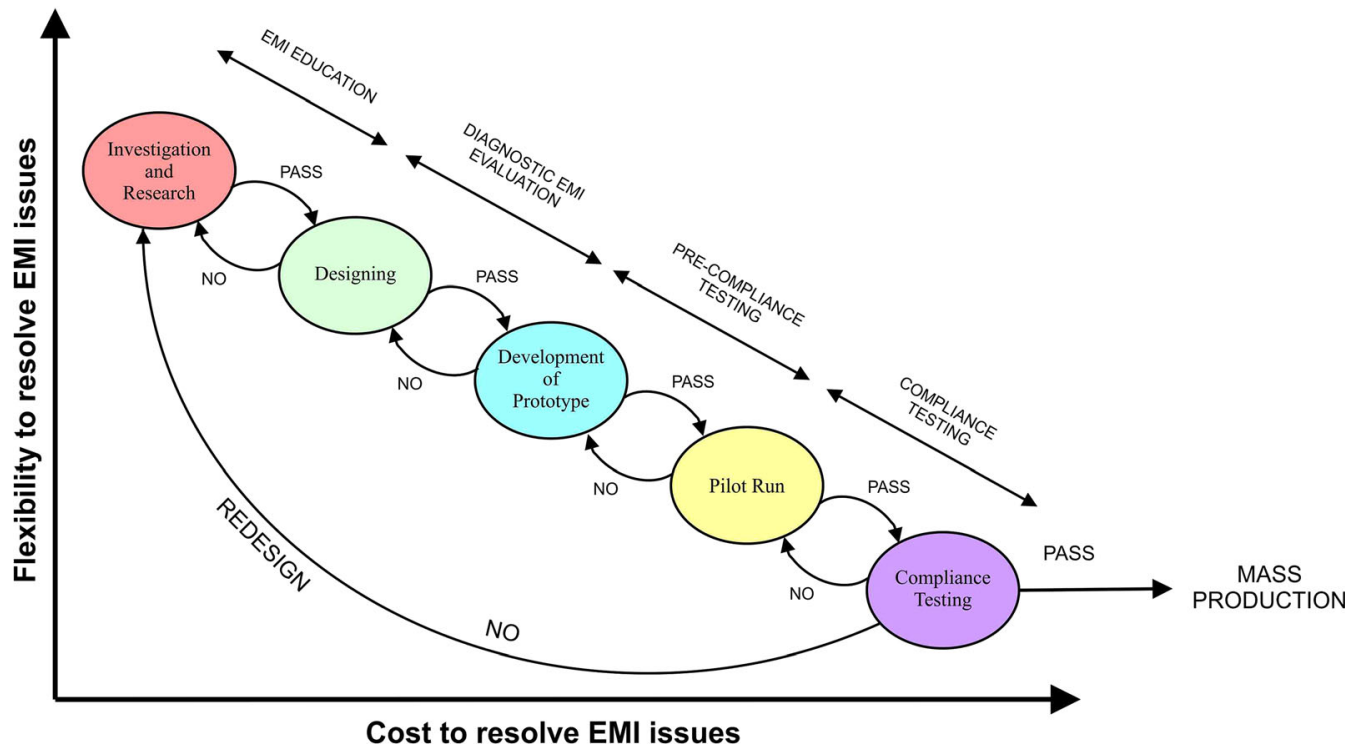

Fig. 1. Electronic product development flowchart.

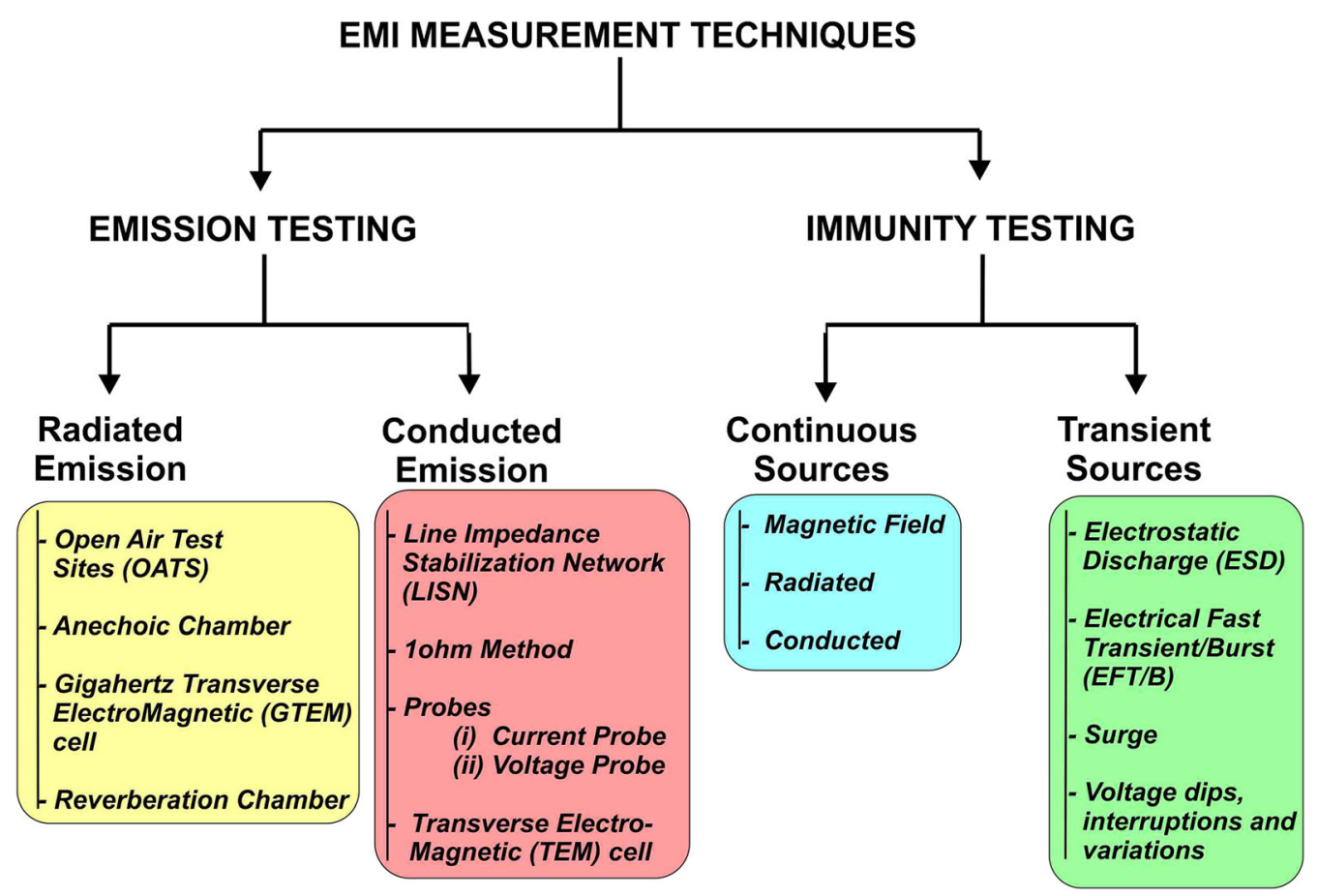

Fig. 2. EMI measurement techniques.

and technique used. There are three main components that aid in the occurrence of EMI viz., emitter/source that acts as the source of unwanted interferences, receiver/susceptor that reacts to these interferences and a coupling channel that transports the interference from the source to the receiver. ${ }^{14}$ If the coupling channel is conducting in nature, then EMI is said to have occurred due to conducted emission. If the coupling channel is of radiating type then radiated emission takes place. These components could be different systems leading to intersystem EMI or they could be different sub-systems of a bigger system leading to intrasystem EMI. ${ }^{4}$ Based on the above categories, EMI measurements/tests are categorized as shown in Fig. 2. 


\section{Emission Testing}

Nearly every electronic instrument acts as a electromagnetic polluter due to intentional or unintentional conducted or radiated emissions originating from it. These unwanted emissions originating from power cables, wires, resistors, capacitors, opamps etc., can go up to the $\mathrm{GHz}$ range and can be conducted through ac power systems (in the case of conducted emission) or through antennas (in the case of radiated emission). Therefore, every electronic instrument must undergo emission testing in order to keep the electromagnetic environment clean and usable for other licensed applications. The emitter in these types of tests is the equipment under test (EUT). As mentioned, emission testing can be done for radiated or conducted emissions. The following sub-sections illustrate different test beds/measurement setups to estimate EMI due to the above mentioned unwanted emissions.

\section{Radiated Emission Testing}

A conventional measurement setup for radiated emission EMI (RE EMI) testing is shown in Fig. 3. Standard radiated emission testing is done within the frequency band of $30 \mathrm{MHz}-1 \mathrm{GHz}$ (corresponding wavelengths are $10 \mathrm{~m}$ and $0.3 \mathrm{~m}$, respectively). ${ }^{15}$ One of the most common methods for radiated emission testing for large instruments is done at an open area test site (OATS). This type of setup usually consists of a theoretically infinite metallic ground plane, a receiving antenna connected to an EMI receiver or spectrum analyzer via cables and the EUT, usually kept at a distance of $3 \mathrm{~m}$ or $10 \mathrm{~m}$ (unless specified differently) from the receiver. ${ }^{16}$ The distance is measured from the nearest outer surface of the EUT to the receiver antenna. ${ }^{17}$ Such a large distance between the EUT and the receiver is primarily chosen to make certain that the measurements are taken in the far field region where radiated field is more stable as compared to that in the near field or Fresnel region. In fact, during the initial days of EMI testing in an
OATS environment, distances of $30 \mathrm{~m}$ were accepted. Such a huge test setup was vulnerable to harsh weather conditions and ambient radio noises that would heavily hamper the accuracy of the measurements. With the advancement of technology and the development of more sophisticated data processing algorithms, it is now possible to carry out these tests at distances of $3 \mathrm{~m}$ or $10 \mathrm{~m} .{ }^{18}$ Currently, researchers are contemplating the idea of using the distance of $5 \mathrm{~m}$ between the EUT and the receiving antenna. The work is still in the initial phase, therefore, the OATS measurement setup with a 5-m distance has not been standardized yet. The size of the EUTs permissible for OATS testing depends on EUT and antenna separation and is specified in standards such as CISPR. 16 EMI due to radiated emissions from the EUT is measured by the receiving antenna for both vertical and horizontal polarizations. The measured field strength is then compared with the maximum field strength as mentioned in the standard which determines whether the EUT has failed or cleared the test.

The radiated emission testing of immensely popular multiple input multiple output (MIMO) systems can be indirectly done using over-the-air (OTA) measurements. The primary objective of OTA tests is to assess the radiation performance of the MIMO system; however, the resulting metric can also be used to determine the deterioration in the receiver sensitivity that is caused by spurious noise signals generated within the MIMO system. One of the most cost-effective and accurate methods to perform OTA testing is known as the two-stage method. In the first stage, all possible three-dimensional radiation patterns are obtained in a standard anechoic chamber for all polarizations. In the second stage, all the obtained patterns are appropriately combined using the desired base station emulator and channel model. ${ }^{19}$ The resultant matrix is then used to determine the RE EMI associated with the MIMO system.

However, for smaller prototypes, these measurements are done in special chambers such as an

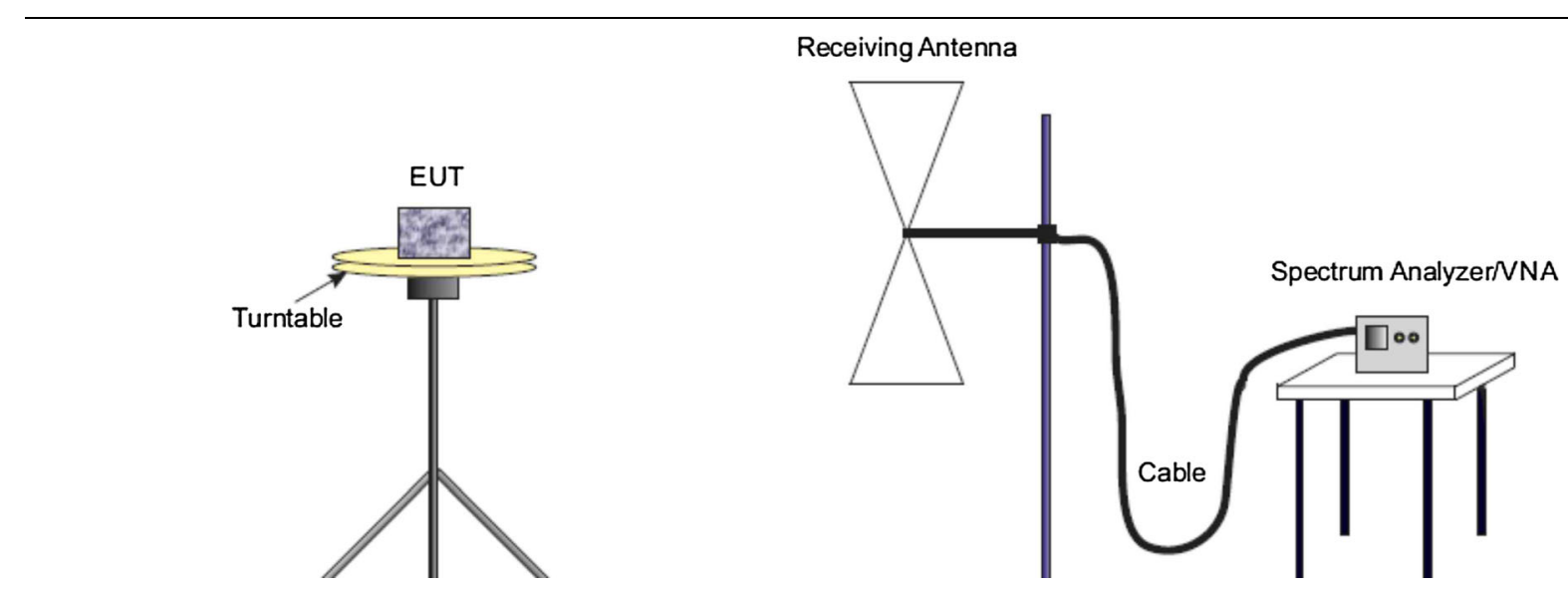

Fig. 3. Radiated emission test set-up in an anechoic chamber (modified and redrawn using the data available in ${ }^{15}$ ). 


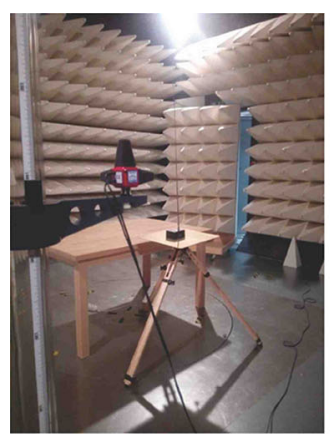

(a)

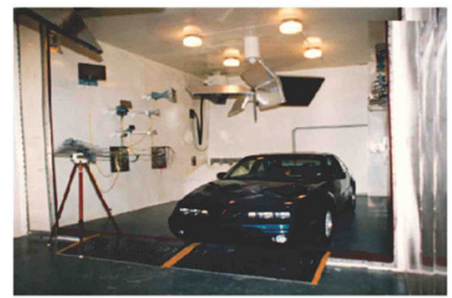

(b)

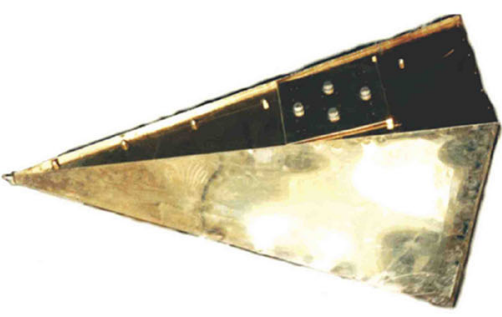

(c)

Fig. 4. Radiated emission testing chambers (a) Anechoic Chamber, adapted with permission from Ref. 21, (b) Reverberation Chamber, adapted with permission from Ref. 23, (c) GTEM cell, adapted with permission from Ref. 25.

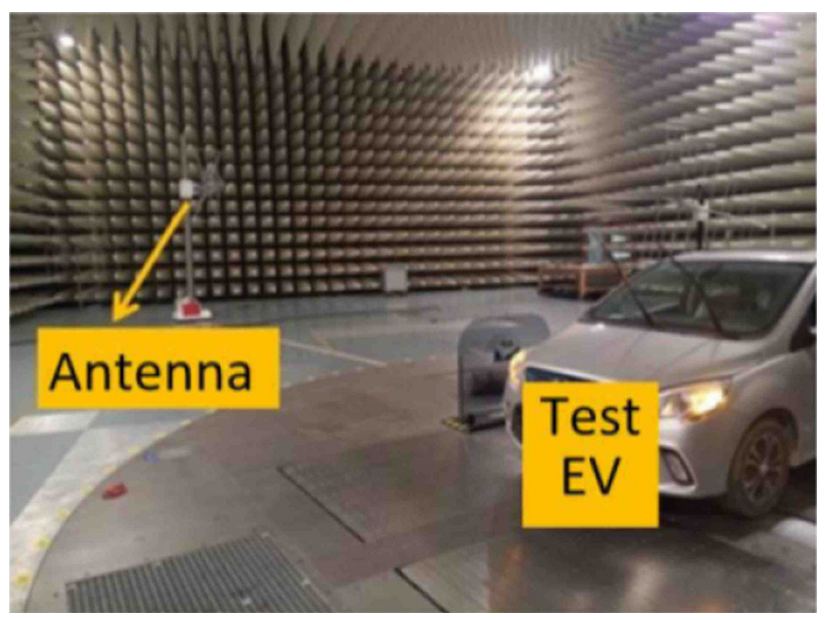

Fig. 5. An example of a test setup to measure radiated emissions in an anechoic chamber (adapted with permission from Ref. 28).

anechoic chamber, ${ }^{20,21}$ or reverberation chamber $^{22,23}$ or a gigahertz transverse electromagnetic cell (GTEM cell). ${ }^{24,25}$ Some typical examples of these chambers are shown in Fig. 4.

1. Anechoic Chamber The walls and floor of an anechoic chamber are fully or partially (for a semi-anechoic chamber) covered with microwave absorbers in order to absorb undesired interferences that can hamper electromagnetic measurements. Park et al. carried out RE tests in a semi-anechoic chamber (SAC) to estimate the interferences due to a cable connected to a mobile instrument by measuring the commonmode current and radiated transfer function associated with the cable. ${ }^{26}$ In 2017 , Dina et al. measured the radiated emissions from a laptop in a SAC. The authors used an IEC 61000-4-3 standard measurement setup and compared their results against EN 55022 (CISPR 22) standard. The analysis was done for the frequency range of $30 \mathrm{MHz}-1 \mathrm{GHz}$. Wang and
Vick carried out these tests in an anechoic chamber, for electrically large EUTs in order to estimate their directivity to correlate the radiated emissions for similar EUTs under different test conditions. ${ }^{27}$ Gao et al. suggested that RE EMI emanating from the battery management system (BMS) of an electric vehicle could render serious damage to the on-board circuitry as well as the operation of a nearby electrical vehicle. They carried out a diagnostic test of an electric vehicle to identify the major sources of emission peaks exceeding the standard limits. The distance between the EUT (electric vehicle) and the receiving antenna was $10 \mathrm{~m}$ and the testing was done in an SAC as shown in Fig. $5 .^{28}$

2. GTEM Cell In addition to an anechoic chamber, GTEM cells are also used to conduct emission tests for EMI measurements. GTEM cell is a tapered two conductor transmission line whose characteristic impedance is required to be kept constant at $50 \Omega .^{29}$ The smaller end of the GTEM cell acts as the input/output (I/O) port while the inner walls of the flared end are covered with $\mathrm{RF}$ absorbers. The I/O port of GTEM is connected to the spectrum analyzer or a network analyzer. ${ }^{30}$ The measurement setup for radiated emission testing using a GTEM cell is shown in Fig. 6. Palczynska measured the emissions due to a portable power bank using a GTEM cell and then extrapolated the results to obtain equivalent OATS field strength using the equation ${ }^{31}$ :

$$
\begin{aligned}
E_{m \mid d B}= & 20 \log \left(g_{m}\right)+20 \log \left(\frac{\left|\eta_{0} \cdot k_{0}\right|}{\left|2 \pi e_{0 y}\right|}\right) \\
& +10 \log \left(\frac{V_{x}^{2}+V_{y}^{2}+V_{z}^{2}}{Z_{c}}\right)+120
\end{aligned}
$$

where $E_{m \mid d B}$, maximum electric field strength; $g_{m}$, variable dependent on the antenna and geometry of the EUT to be used in the OATS setup; $k_{0}$, wave number; $\eta_{0}$, free-space impedance; $e_{0 y}$, field in TEM mode; $Z_{c}$, characteristic impedance; $V_{x}, V_{y}$ and $V_{z}$, 


\section{Spectrum analyzer}

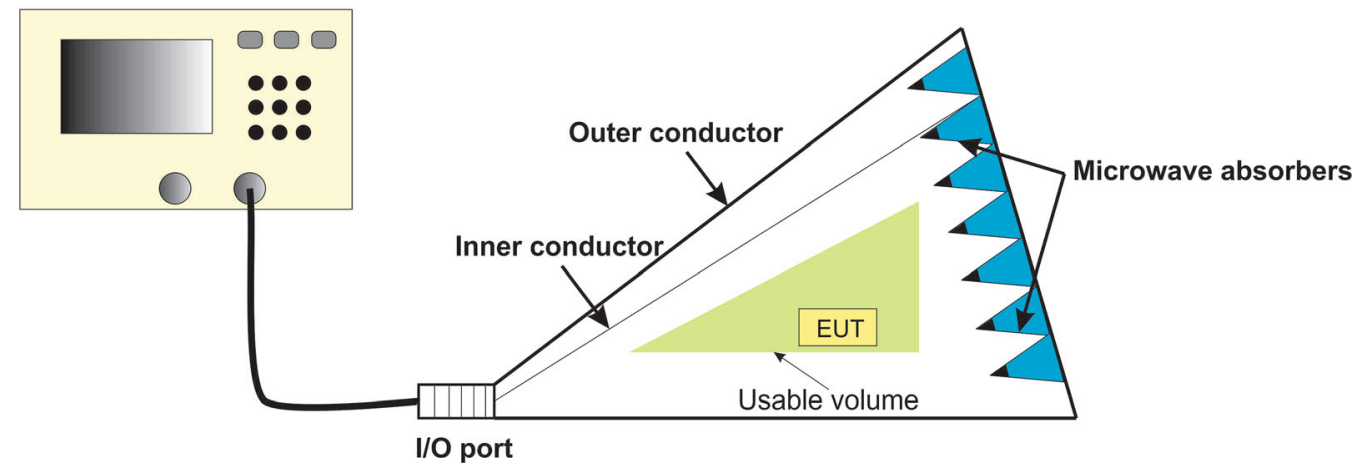

Fig. 6. Measurement setup for EMI testing using a GTEM cell (modified and redrawn using the data available in Ref. 25).

output voltages in three orthogonal directions along which the EUT is sequentially oriented.This was done in order to make sure that the results obtained are in compliance with the standards. Chua et al. reported the measured radiated emission test results of an IC against the international standard IEC 61967-2. According to this standard, the IC board must be mounted on the wall port of GTEM cell. $^{32}$ The biggest advantage that the GTEM cell provides when compared to OATS or anechoic chamber setups is that it is much more affordable and compact (hence easy to maintain). Moreover, GTEM cells can provide reasonably accurate results from $0 \mathrm{~Hz}$ to $20 \mathrm{GHz}{ }^{30}$

3. Reverberation Chambers (RC) An RC is a metallic enclosure with a high quality factor (Q) that most commonly contains a transmitting antenna, a receiving antenna and EUT. Its metallic boundary gives rise to standing waves that, in turn, create an inhomogeneous electric field inside the chamber. One or multiple metallic paddles called stirrers are placed inside the chamber. The orientation of the stirrers could be controlled to modify the boundary conditions of the chamber such that the electric field becomes statistically homogeneous. ${ }^{33}$ A standard reverberation EMC testing facility is shown in Fig. $7 .^{22}$ The biggest advantage of using a reverberation chamber for EMI testing is that it gives more accurate and reliable results in a shorter span of time when compared to its counterparts, especially in radiated immunity testing. ${ }^{34}$ This is because the EUT, unlike in the anechoic chamber, is subjected to an external field from all directions simultaneously. Hence, the need to mechanically rotate the EUT in the desired directions for measurements is eliminated. However, the information about the directivity and polarization is compromised. Since, there is no need to put expensive microwave and $R F$ absorbers in the chamber, this method is highly economical. ${ }^{35}$

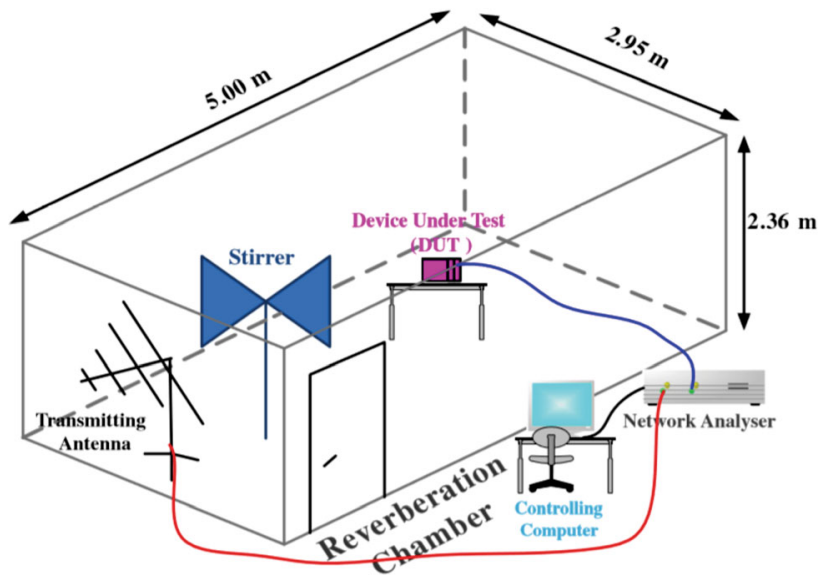

Fig. 7. Measurement setup for EMI emission testing using a reverberation chamber (adapted with permission from Ref. 22).

\section{Conducted Emission Testing}

Conducted emission testing is done to estimate/ determine the noise, generated due to a sudden change in voltage or the current in the circuitry of the equipment, being emitted through the power lead into the peripheral/loaded devices. ${ }^{36}$ The unwanted noise could have a fatal effect on the connected devices and may lead to the malfunction of the equipment. Some popular methods employed for conducted emission testing are ${ }^{37}$ :

1. Line impedance stabilization network (LISN)

2. $1 \Omega$ method

3. Probes

(a) Current probe

(b) Voltage probe

4. Transverse electromagnetic (TEM) cell

1. Line Impedance Stabilization Network (LISN) When an LISN is placed between 


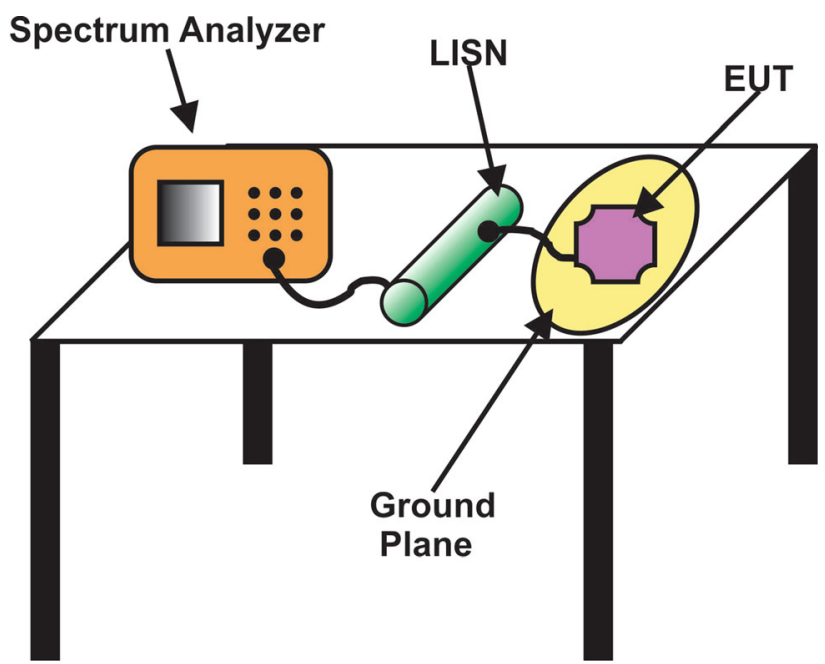

Fig. 8. Measurement setup for EMI conducted emission testing using a line impedance stabilization network (LISN) (modified and redrawn using the data available in Ref. 37 ).

the EUT and power source, the noises due to variations in the ac power source impedance can be eliminated. ${ }^{38}$ An LISN provides a stable impedance at single frequency to the EUT. The noise voltage is then measured following the methodology illustrated in CISPR $25,2010 .{ }^{37}$ The RF port of the LISN is connected to the measurement receiver that gives the noise voltage. ${ }^{36}$ A typical measurement setup for conducted emission testing using an LISN is shown in Fig. 8. This method can provide accurate results up to $100 \mathrm{MHz}$; therefore, it cannot be used in high-frequency circuits.

2. $1 \Omega$ The $1 \Omega$ noise measurement, presented in IEC 61967-4, involves the estimation of conducted emission noise by measuring the voltage drop across the external resistances that are placed in series with the pins of the EUT. ${ }^{39}$ The accuracy of this method spans in the gigahertz range. However, this method loses feasibility if the EUT has a large number of pins.

3. Probes Probes provide a more direct method to compute the conducted emission from the EUT. Current probes work on the principle of current transformer with the power lead of the EUT acting as a primary coil and the probe itself acts as a secondary. ${ }^{36}$ The probe consists of a wire coiled around a ferrite core. Voltage probes are also used to measure noises due to conducted emissions. A small resistance is connected to the voltage probe and an oscilloscope with high sensitivity. The voltage across the resistor is ascertained and then, using FFT, is transformed into the current spectrum. ${ }^{40}$
4. Transverse Electromagnetic (TEM) Cell A TEM cell was first developed by Crawford in 1974 and is a major facility that is used for emission testing. ${ }^{41}$ It is, in fact, a version of a GTEM cell that works on frequencies from $0 \mathrm{~Hz}$ to several $\mathrm{MHz}$. Basically, it is a transmission line which is tapered at both ends for impedance matching. ${ }^{42}$ For conducted emission testing, the EUT is placed inside the cell which is connected to a port of $50 \Omega$ impedance and a spectrum analyser on the other port. The EUT radiates the noise within the cell which is propagated to the terminals. The EUT is connected to the LISN which is connected to the power supply. The $\mathrm{RF}$ port of an LISN is terminated with $50 \Omega{ }^{37}$

\section{Immunity Testing}

Immunity testing is the exact opposite of emission testing. While in emission testing the noise radiating from the EUT was measured, immunity testing refers to the process of subjecting the EUT to an electromagnetically hostile environment and then assessing the presence or absence of any modification in the performance of the EUT. If any change in the functioning of the EUT is perceived, then it is quantified and compared against international or national standards as per the requirement. If the instrument fails to pass these tests then it is rendered incapable of performing efficiently in the real world. In this sub-section, techniques used in immunity measurements for pre-compliance or compliance EMI testing are explained under two different classes, namely continuous and transient.

\section{Continuous Source Immunity Testing}

Continuous immunity testing is aimed at determining if the EUT will function as intended when it is exposed to continuous noise sources such as the cosmic microwave background, solar radiation, broadcast stations, motor vehicles, magnetic fields. ${ }^{4}$ Continuous source immunity testing is done for a few or several minutes. This category of testing can be further categorized into magnetic field, radiated and conducted immunity testing.

1. Magnetic Field Immunity The cables and wires of an electrical instrument give rise to magnetic fields that can attack magnetically sensitive components such as relays and monitors of the parent circuit and instruments present in close proximity. Hence, it becomes extremely important to check whether a device can withstand such adversities. IEC/EN61000-4-8 is the standard most commonly used to carry out the mentioned test. The setup consists of a signal 
generator connected to a loop antenna or Helmholtz coil. The EUT sits within the antenna/coil in order to be exposed to a continuous magnetic field. ${ }^{43}$ Other standards also used for magnetic field immunity testing are IEC/EN61000-4-9, IEC/EN61000-4-10 etc. ${ }^{4,45}$ In 2018, Yang et al. proposed a test setup that incorporated the use of a two-coil system instead of Helmholtz coil. They were able to prove that the two-coil system had similar results as the Helmholtz coil system with reduced mass and lower electrical dissipation. ${ }^{46}$

2. Radiated Immunity (RI) RI testing is done to assess the tolerance of an instrument against the electromagnetic energy present in its freespace environment. IEC $61000-4-3$ is the standard most commonly used for radiated immunity. RI tests are usually done in OATS, anechoic chambers, GTEM cells and reverberation chambers. ${ }^{47-51}$ The measurement setup involves an RF signal generator that provides a continuous electromagnetic signal at different frequencies, a power amplifier to amplify the generated signal, a transmitter antenna, such as a log-periodic antenna, or a biconical antenna, to transmit the generated signal into the chamber/cell and create a uniform field environment, an EM field sensor to monitor the field strength within the chamber/cell, a table on which the EUT is placed, an EUT and a monitoring system that can monitor the health of the EUT. The preferred distance between the antenna and EUT is $3 \mathrm{~m}$ or $10 \mathrm{~m} \cdot{ }^{52}$ For each face of the EUT facing the transmitter antenna, its performance is repeatedly assessed for different frequencies, different signal strengths, appropriate modulations and different polarizations of the antenna. A typical measurement setup for RI testing is shown in Fig. 9.

In 2009, Armstrong showed that RI testing as specified by the standards might not be suffi- cient and accurate to assess the performance of the equipment in the real world scenario. The author pointed out some issues regarding the reliability of test levels, angle of incidence and polarization of the field inside the chamber/cell, susceptibility of the equipment towards certain frequencies and negligence towards the factors such as ageing and corrosion. He proposed a checklist of the factors that must be taken into account while performing these tests. ${ }^{53}$ In the same year, Tang et al. also realized the inaccuracies in the standard $\mathrm{RI}$ testing for medical equipment and proposed a technique to check the tolerance level of medical instruments

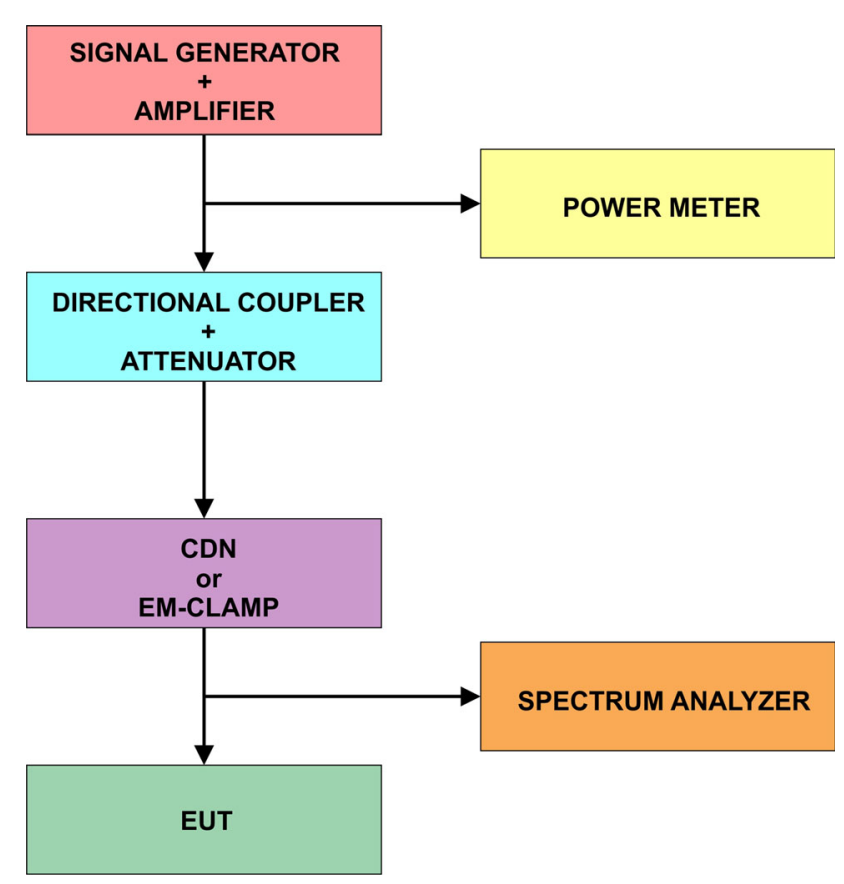

Fig. 10. Block diagram for EMI conducted immunity testing (modified and redrawn using the data available in Ref. 55).

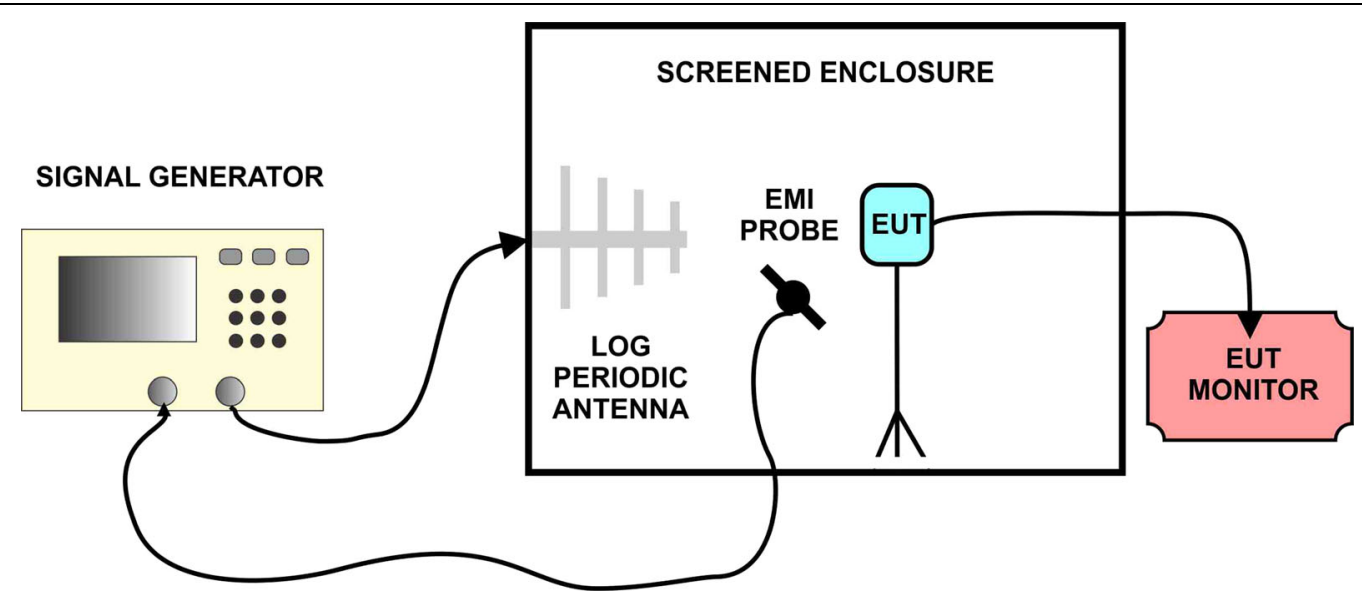

Fig. 9. Measurement setup for EMI radiated immunity testing (modified and redrawn from the data available on https://www.laplace.co.uk/iec 61000-4-3/). 
against the radiations due to mobile phones. ${ }^{54}$

3. Conducted Immunity (CI) Radiated emissions or induced inductance and capacitance due to the bending of power cables can be picked up by cables and connectors of an electronic system as spurious RF voltages and currents. These currents can then propagate to other system components as conducted interference and can cause degradation in the overall performance of the system. IEC-61000-4-6 is one of the widely accepted standards for CI testing and it is done in the frequency range of $150 \mathrm{kHz}-$ $80 \mathrm{MHz}$. A block diagram of CI testing is shown in Fig. $10 .{ }^{55}$ The setup includes an RF signal generator that simulates the interference signals. These signals are then coupled to the EUT, in common mode with respect to ground plane via an amplifier and an injecting device such as a coupling/decoupling network (CDN), ${ }^{56}$ EM clamp $^{57}$ or a BCI probe. ${ }^{58}$ The performance of the EUT is then analyzed using a spectrum analyzer or any other monitoring system. ${ }^{55}$ Because of certain limitations such as the physical dimensions of the EUT, it is not always possible to use the above mentioned injection devices to conduct these tests. Cakir et al. proposed an alternative method to measure the conducted immunity of a device by measuring the impedances of test loops using two current probes. ${ }^{59}$

\section{Transient Source Immunity Testing}

Even though transient sources of electromagnetic interference such as lightning, EM pulses, electrostatic discharge, voltage fluctuations, fast switching and relaying take place for a tiny duration of time, they can have a catastrophic effect on system performance. Electronic systems on board an airplane or spaceship, or equipment used in meteorology to monitor storms, tornadoes, etc. are some examples of potential casualties of transient EMI. Checking the system's tolerance in these events, therefore, becomes extremely crucial. ${ }^{60}$ Since transient sources release a large amount of EM energy for a small duration of time (not more than a few milliseconds), the immunity testing of a system against them is done in the time domain. ${ }^{4}$ In this sub-subsection, transient source immunity testing is discussed under five conditions, namely, electrostatic discharge (ESD), electrical fast transient (EFT), surge, pulsed magnetic field and voltage variations.

1. Electrostatic Discharge (ESD) ESD refers to a sudden transfer of a large quantity of charge from one potential to another in a very short duration of time (a few nanoseconds), causing the generation of an intense electric field. This electric field can cause temporary or permanent damage to nearby electronic systems. ${ }^{61}$ A general example of ESD is the shock that a person would feel when touching a metallic object. While humans can withstand that type of EM energy, most electronic equipment and integrated circuits (ICs) cannot. ${ }^{62}$ ESD can occur due to factors such as improper insulation or defective grounding in the circuit of the instrument. It can hamper or interfere with the operations of an electronic device in three ways $^{63}$ :

- Direct contact discharge

- Discharging through an air gap

- Indirect discharging through a vertical plane

IEC $61000-4-2$ is the internationally accepted system level standard for immunity testing of an electronic device against $\mathrm{ESD}^{64}$ and the required test voltage levels for contact discharge and air discharge immunity testing, prescribed by it are shown in Table I. ${ }^{63} X$ can take any value above, below or in between the specified values. $X$ strictly depends upon the equipment specification. If the test voltage required is much greater than the specified voltages, then additional appropriate equipment might be required for ESD immunity testing. Standard IEC 61000-4-2 states that contact discharge is sufficient to check the immunity of an electronic system while indirect discharge immunity testing is done only when it is specifically required. Air discharge immunity testing is more complicated as reproducibility is not guaranteed by it. $^{63,65}$

Schematic of measurement setup for ESD immunity testing is shown in Fig. $11 .^{66}$ It consists of a reference ground plane on which the non-conducting table is placed. The top of this table is partially or fully covered with a horizontal conducting sheet

Table I. Test levels and voltages for ESD immunity test

\begin{tabular}{|c|c|c|c|c|c|}
\hline Test level & $1(\mathrm{kV})$ & $2(\mathrm{kV})$ & $3(\mathbf{k V})$ & $4(\mathrm{kV})$ & $\mathbf{X}$ \\
\hline Contact discharge voltage & 2 & 4 & 6 & 8 & Special \\
\hline Air discharge voltage & 2 & 4 & 6 & 15 & Special \\
\hline
\end{tabular}




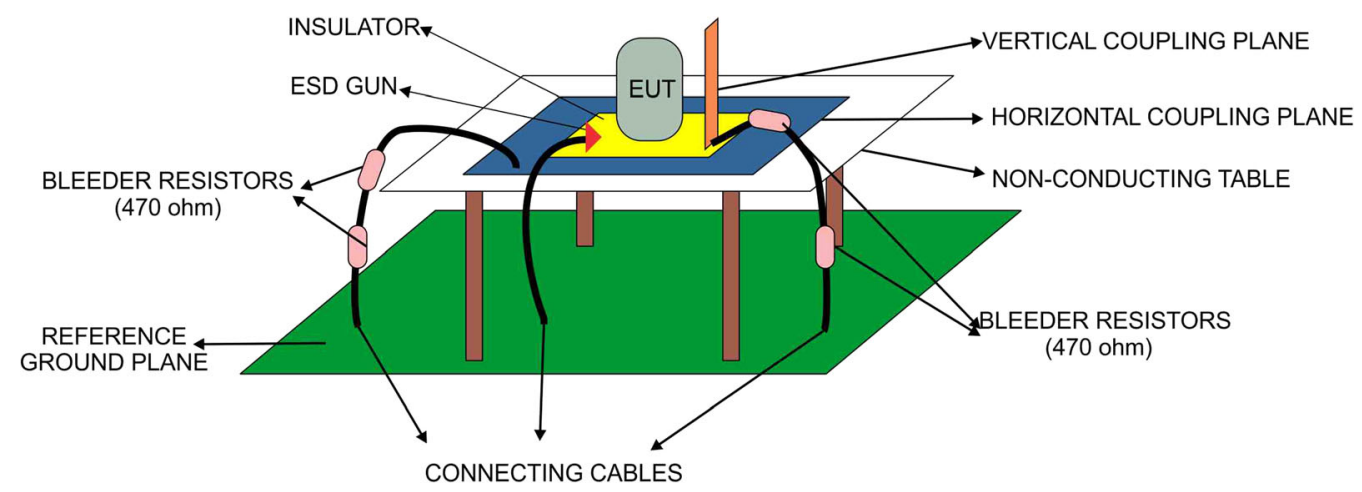

Fig. 11. Measurement setup for ESD immunity testing (modified and redrawn using the data available on https://www.atecorp.com/compliancestandards/iec/iec-61000-4-2).

to facilitate direct contact ESD testing. The EUT is placed on the horizontal conducting sheet with a insulator sheet in between. A vertical coupling sheet is placed at a distance of $10 \mathrm{~cm}$ from EUT, on the insulator, to take measurements for indirect discharge. An ESD gun is placed opposite from the EUT to simulate the discharge and is connected to the reference ground plane via low loss cables. The reference ground plane is connected to both horizontal and vertical conducting plane via two $470 \Omega$ bleeder resistors. According to IEC 61000-4-2 standard, the optimum temperature of the lab should be $15^{\circ} \mathrm{C}-35^{\circ} \mathrm{C}$ and the relative humidity should fall between $30 \%$ and $60 \%{ }^{67}$

The test procedure involves the application of discharge from the ESD gun to the EUT at an interval of $1 \mathrm{~s}$. The ESD gun can be placed directly in contact with the EUT for direct measurements or behind the vertical conducting plane for indirect measurements.

Nagai et al. used the indirect ESD test method to measure the EMI due to ESD between the human body and a wearable biosensor by treating the human body as an equivalent receiving antenna. ${ }^{68}$ However, studies have suggested that the standards specified by IEC $61000-4-2$ are inadequate to determine the adverse effects of ESD on the functioning of wearable devices, and hence new standards are required for such equipment. ${ }^{69-74}$

2. Electrical Fast Transient/Burst (EFT/B) When an inductive load such as a motor, relay, or solenoid is switched from one state to another then a short pulse or a burst of short pulses of currents and voltages is generated and is known as electrical fast transient/burst (EFT/B) ${ }^{75}$ These pulses have the lowest rise time, ranging from nanoseconds to milliseconds, as compared to other pulsed EMI noises. Moreover, they have a high repetition rate along with low energy and can cause permanent damage to the ICs and other circuit components. ${ }^{76}$ Since most modern electrical instruments consist of digital circuitry usually containing switches and relays, the EFT/B immunity test is one of the most important tests that the instrument should clear. IEC 61000-4-4 is the standard that specifies the setup and method to carry out EFT/B immunity testing. ${ }^{77}$

The method of EFT/B testing is quite straight forward. Single pulse transients of a rise time of $5 \mathrm{~ns}$ and a duration of $50 \mathrm{~ns}$ and a burst of short pulses for a duration of $15 \mathrm{~ms}$ with repetition rate of $5 \mathrm{kHz}$ (or $0.75 \mathrm{~ms}$ with repetition rate $100 \mathrm{kHz}$ ) with a time interval of $300 \mathrm{~ms}$ are applied for $1 \mathrm{~min}$ on each line to be tested in each polarity. ${ }^{78}$ The waveform transients are applied in a common mode so that is each line is fed simultaneously. Voltage requirements depend upon the product and the type of line to be tested and are specified by the product standards. ${ }^{79}$ Another standard that lays out the details of EFT/B immunity testing is IEC 62228. Many studies have been conducted to investigate the adverse effect of fast transients on controller area networks (CANs) using this standard. ${ }^{80-83}$ According to this test, EFT/B transients are injected through capacitance coupling and the immunity is determined by measuring the voltages and currents.

$\mathrm{Wu}$ et al. used a non-standardized test based on Langer EMV Technik to conduct an EFT/B immunity test on two microcontroller units with different architectures. Langer EMV Technik is based on the use of probes to inject the fast transient noise into the EUT. Their measurement setup is shown in Fig. 12. ${ }^{84}$ Zhang et al. also conducted some non-standardized EFT/B immunity tests to examine the effect of EFT/B on multilayered ceramic capacitors. They used high voltage $(\mathrm{HV})$ relays to simulate and inject the short pulses to the capacitors. HV differential probes and a oscilloscope were used to measure the voltage across the capacitor generated during the applied pulsed noises. ${ }^{85}$ 


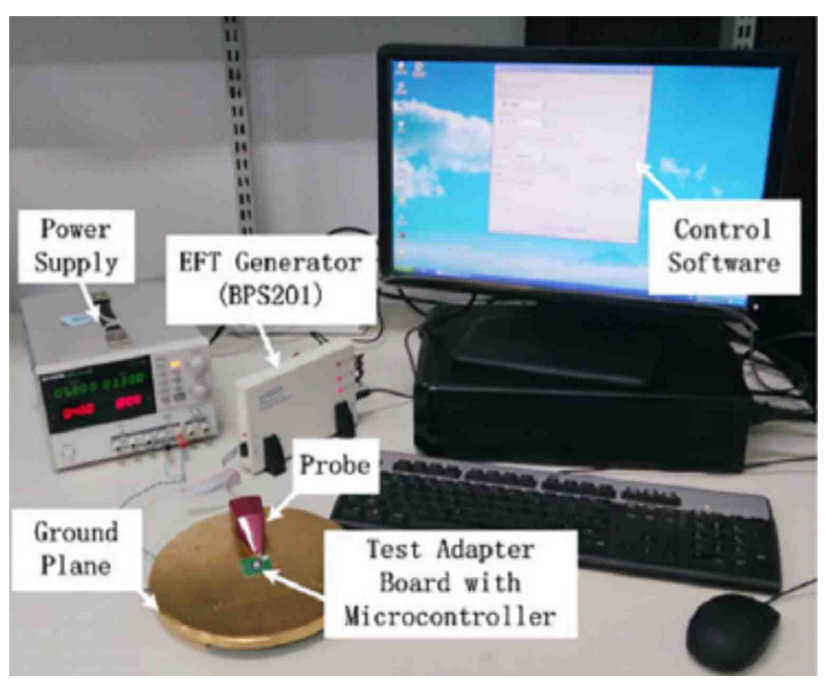

Fig. 12. Measurement setup based on Langer EMV Technik (adapted with permission from ${ }^{84}$ ).

3. Surge Spurious overvoltages and currents generated due to bulk capacitive load switching and lightning constitute surge interference noises. These interferences can prove to be fatal for the electronic system. ${ }^{86}$ Surges are relatively low frequency and high energy transient noises with rise time on the order of a few microseconds and a duration of about a few tens of microseconds. ${ }^{87}$ IEC $61000-4-5$ is the standard that specifies the test conditions and methods to measure the immunity of an electronic system from these transients. ${ }^{88,89}$ Two generators are used to simulate surges in main power line of the EUT via a decoupling network and I/O line via decoupling and protection network (Zener diodes, varactors etc.). The maximum repetition rate of surges applied to the setup depends on the device; however, on average 10 surges are applied at each level with a time interval of not more than $1 \mathrm{~min}$. Also, as a precaution, the EUT and other components used during the test are physically isolated so as to avoid the adverse effect of flashovers. ${ }^{79}$ Usually, a single electrical system undergoes this test at a time; however, in 2016 D. W. Harberts proposed that if seven samples are tested simultaneously then the accuracy of the test doesn't diminish and much time in the largescale production cycle is saved..$^{90}$

(iv) Voltage Dips, Interruptions and Variations EN 61000-4-11 is the standard to test the tolerance of the electronic system to voltage dips, interruptions and variations that can occur due to the imperfections in the distribution systems. ${ }^{91} \mathrm{~A}$ voltage dip refers to a sudden drop in the ac supply voltage for a short duration of time, followed by the restoration of the original waveform. On the other hand, voltage interruptions occur when the supply voltage apparently disappears for a short interval and then reappears in its original form. As the name suggests, voltage variations happen when the supply voltage becomes higher or lower than the rated voltage. ${ }^{92}$ These anomalies in the supply voltage can deeply hamper the power quality factor of the electronic system. They may induce short circuiting and even explosion. Devices such as a UPS aim at mitigating this phenomenon. ${ }^{93}$ Since the compactness of an electronic system is preferred, having an additional device to stabilize voltage fluctuations is not always ideal. Therefore, the electronic systems must be inherently susceptible to these voltage variations.

The desired lab conditions during the test are quite flexible as long as the electromagnetic environment does not interfere with the EUT's operations. the test setup includes a generator that simulates the voltage variations connected to the EUT via good quality, low EMI cables. A generator/simulator is required to provide a peak inrush current of $500 \mathrm{~A}$ for an average of $230 \mathrm{~V}$ mains. The significance of inrush current lies in the fact that it is often the biggest factor that causes serious damages to electronic systems as far as voltage variations are concerned. During the test, each of the above mentioned voltage stresses are applied three times with a gap of $10 \mathrm{~s}$. After each group of test, a full functional test of EUT is conducted to check if any degradation in the performance has happened.

\section{EMI REDUCTION TECHNIQUES}

If the instrument under consideration fails any of the EMI tests discussed before, then a number of ways can be adopted to reduce the associated EMI and make the instrument compatible with the realworld electromagnetic environment. This section presents these techniques under four subsections viz. electromagnetic shielding, EMI filters, circuit topology modification and spread spectrum. Special emphasis has been given to electromagnetic shielding as it is probably the most popular method incorporated in the product design.

\section{Electromagnetic Shielding}

One of the most popular methods to reduce EMI and its effect on an electronic system is the use of electromagnetic shields. These shields, as shown in Fig. 13, are enclosures made of conductive materials such as metals, conductive polymers, metamaterials, and ferrites that encase an electronic component and heavily attenuate the interfering noises associated with it. When the EMI field 


\section{EM environment adulterated with EMI}

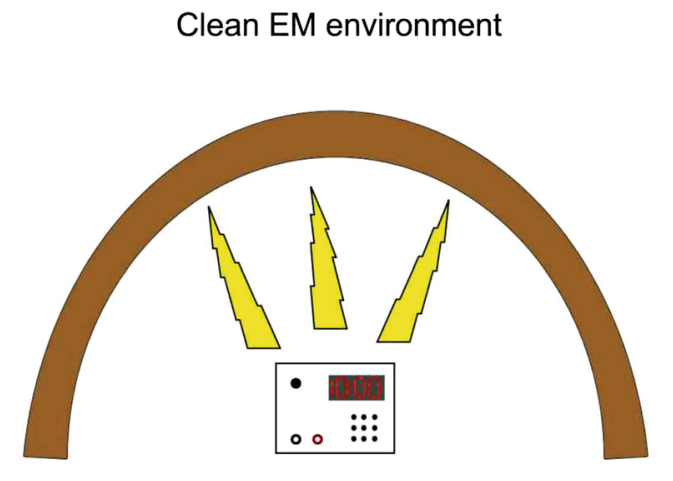

EM environment adulterated with EMI

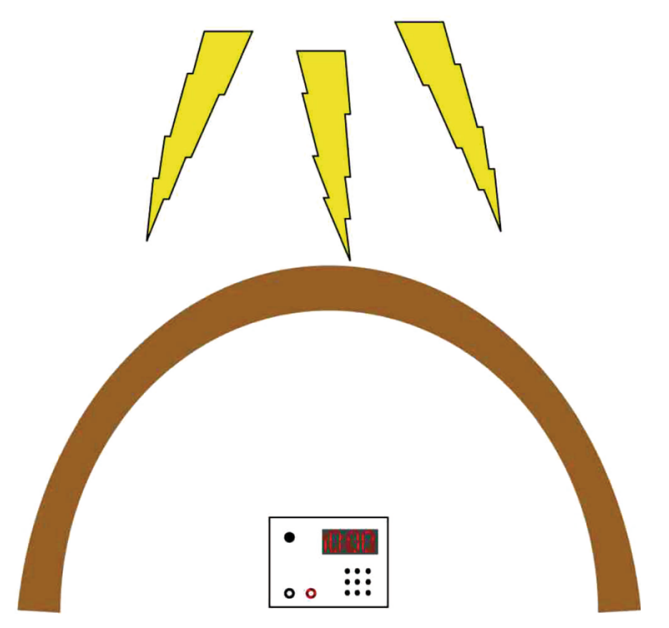

Clean EM environment

Fig. 13. Electromagnetic shielding.

impinges on the shield then a major portion of this field gets either reflected or absorbed and a very small portion gets transmitted. The combined effect of all these phenomenon is addressed as the EMI shielding effectiveness (EMI SE) of the structure, which is the ratio of EM power before the shielding effect to the EM power after the shielding effect in decibels ${ }^{94}$ :

$$
S E=10 \log \left(\frac{P_{r x}}{P_{r x^{\prime}}}\right)
$$

where $P_{r x}$ is the power intercepted by the receiver in the absence of the shield and $P_{r x^{\prime}}$ is the power intercepted by the receiver when the shield is placed between the receiver and the transmitter (noise source). Permeability, conductivity, permittivity etc. are the properties of the material that, along with factors such as the frequency at which the measurement must be done, the polarization and angle of incidence of the impinging wave, near-filed or farfield application, govern its EMI SE. There are numerous techniques to measure the EMI SE of a particular EMI shielding system, some of which are enumerated below:

- Coaxial Transmission Line Method

- Dual TEM Cell Method

- Rectangular Waveguide Method

- Nested Reverberation Chamber Method

- Shielded Box Method

- Shielded Room Method

- Free-Space Method

\section{Coaxial Transmission Line Method}

This method is probably the most preferred technique to measure the SE of an isotropic planar

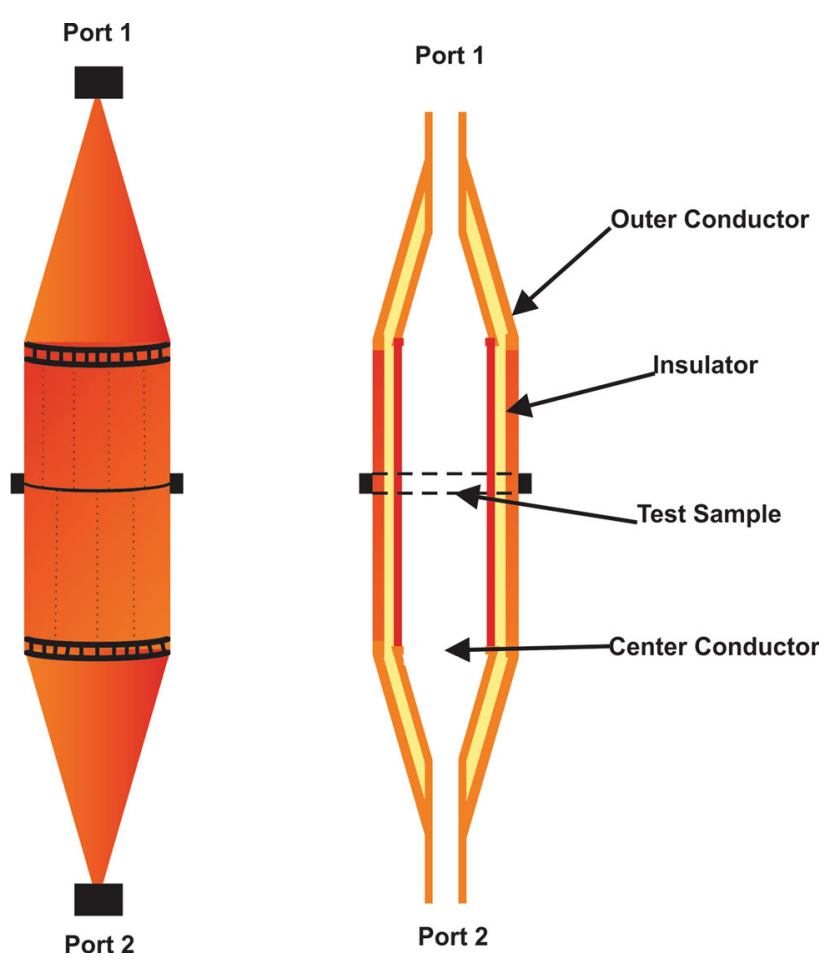

Fig. 14. Coaxial transmission line fixture used in an ASTM ES7-83 setup (modified and redrawn using the data available in Ref. 104).

material with respect to plane waves falling normally over its surface. Two well-known standards have been developed based on this technique, namely, ASTM ES783 and ASTM D493510. ${ }^{95}$ According to the first method, a torus-shaped sample is placed at the center of a coaxial cell which is tapered at both ends to match $50 \Omega$ impedance as shown in Fig. 14. The inner and outer diameters of the sample are matched with the diameters of the 
inner and outer conductor of the coaxial fixture which are $4.35 \mathrm{~cm}$ and $9.9 \mathrm{~cm}$, respectively. The input and output powers are measured using a network analyzer and substituted in (2) to compute the shielding effectiveness of the material. Analytically, the calculation of SE of the sample is based on the fact that the TEM wave propagating in the coaxial transmission line mimics the far-field incident plane wave while the sample acts as a load. The EMI SE of the sample is then computed using the following formula ${ }^{96}$ :

$$
S E=20 \log \left|1+\frac{Z_{0}}{2 Z_{L}}\right|
$$

where $Z_{0}$ and $Z_{L}$ are the characteristic impedance of the coaxial transmission line and impedance presented by the load, respectively. This expression is applicable when a perfect contact between the transmission line walls and sample is established. However, practically achieving a perfect contact is extremely difficult. Such imperfections lead to the generation of a contact resistance $Z_{C R}$ in series with $Z_{L}$, which participates in $\mathrm{SE}$ determination as follows:

$$
S E=20 \log \left|1+\frac{Z_{0}}{2\left(Z_{L}+Z_{C R}\right)}\right|
$$

The technique to measure the SE of a material is very simple but lacks accuracy and is not repeatable as the $Z_{C R}$ may vary for different tests. Because of these reasons, the standard ASTM ES7-83 that was based on this technique was withdrawn in 1988. However, this technique is still very popular to make some crude lab estimations regarding the $\mathrm{SE}$ of a material.

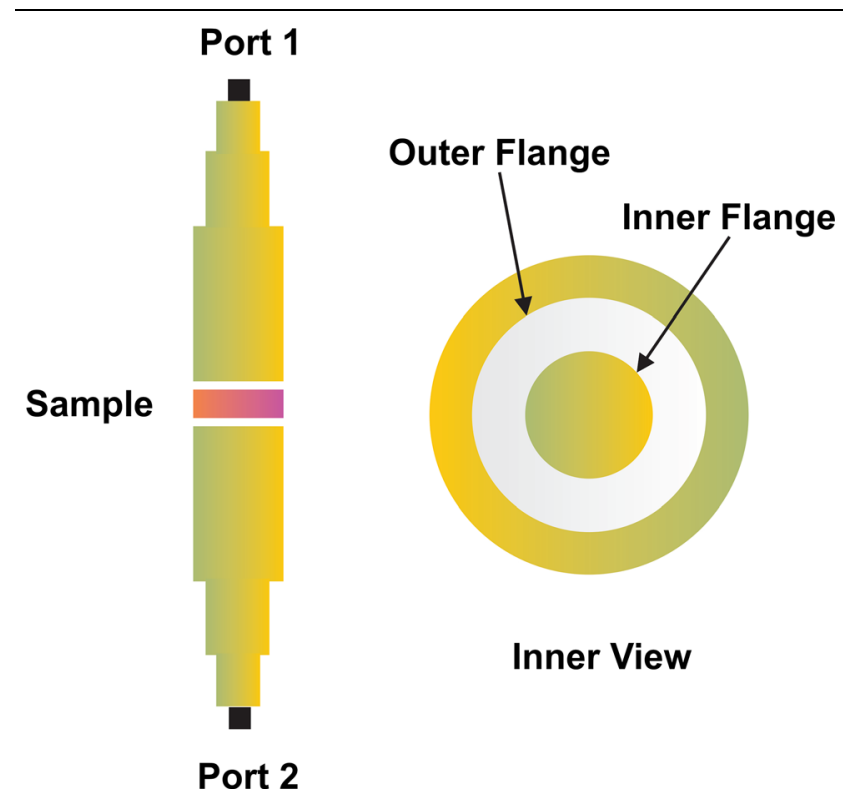

Fig. 15. Flanged coaxial transmission line fixture used in an ASTM D4935-10 setup (modified and redrawn using the data available in Ref. 103).
The above technique was upgraded by replacing the tapered coaxial transmission line cell with a flanged coaxial transmission line as shown in Fig. 15. In this method, SE determination is done in two steps. In the first step, a disc-shaped sample of diameter $13.3 \mathrm{~cm}$ is placed at the center of the test fixture and $S_{21}$ is obtained using the vector network analyzer. The second step gives the reference transmission coefficient by placing the torusshaped sample matching the dimensions of the outer flange and a disc-shaped sample matching the dimensions of the inner conductor. The two pieces of sample are coupled capacitively. Non-conductive screws are used to join the flanged coaxial line together. Conductive switches are avoided as the contact resistance created by them is coupled in series with the load impedance, while that due to non-conductive switches is coupled in parallel with the load impedance. Therefore, the effect of contact resistance is minimized in this method.

Repeatability is the biggest advantage of this method. The coaxial transmission line methods provide very good results for frequency range of $30 \mathrm{MHz}-1.5 \mathrm{GHz}$. However, efforts have been made to enhance this frequency range up to $18 \mathrm{GHz}{ }^{95,97}$

\section{Dual TEM Cell Method}

While the coaxial transmission line method can calculate shielding effectiveness of a material using far-field source simulation, the dual TEM cell method can calculate the shielding effectiveness of a material using near-field sources. Near-field calculations are done mainly to determine the strength of the shield against certain EMI emissions taking place in close proximity. ${ }^{98}$ Conventionally, this method is used to assess the SE of a material within $1 \mathrm{MHz}-1000 \mathrm{MHz}$ frequency range. A dual TEM cell consists of two rectangular coaxial transmission lines tapered at each end for $50 \Omega$ impedance and placed on top of each other. At the interface of the two rectangular transmission lines, there is a rectangular slot to hold the sample as shown in Fig. 16. One of the two cells can act as a driving cell (here, the lower cell) through which the energy is coupled to the receiving cell (here, the upper cell) via the aperture that is covered with the sample.

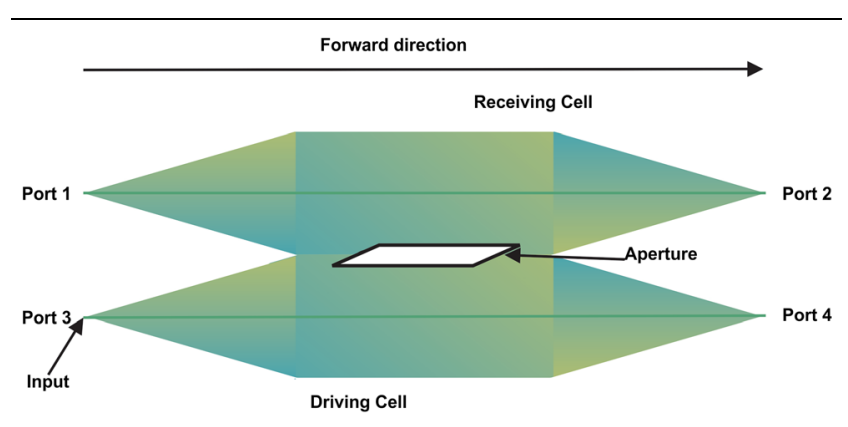

Fig. 16. Schematic of shielding effectiveness measurement using a dual TEM cell setup (modified and redrawn using the data from Ref. 99). 
Since the energy is coupled asymmetrically, the status of a normal electric field component and tangential magnetic field component can be analyzed individually that in turn helps in calculating the shielding effectiveness of the material as described in. ${ }^{98}$ Practically, EMI SE of the sample is computed using the equations below ${ }^{99}$ :

$$
\begin{array}{r}
S E(d B)=20 \log \left|\frac{S_{23}(\text { unloaded })}{\left.S_{23} \text { (loaded }\right)}\right| \\
(\text { forward }- \text { coupling }- \text { mode }) \\
S E(\mathrm{~dB})=20 \log \left|\frac{\left.S_{13} \text { (unloaded }\right)}{S_{13}(\text { loaded })}\right| \\
\quad \text { (backward }- \text { coupling }- \text { mode }) \\
\operatorname{SE}(\mathrm{dB})=20 \log \frac{\left|S_{23}+S_{13}\right|(\text { unloaded })}{\left|S_{23}+S_{13}\right|(\text { loaded })} \\
\quad(\text { electric }- \text { coupling }- \text { mode }) \\
\operatorname{SE}(\mathrm{dB})=20 \log \frac{\left|S_{23}-S_{13}\right|(\text { unloaded })}{\left|S_{23}-S_{13}\right|(\text { loaded })} \\
\quad(\text { magnetic }- \text { coupling }- \text { mode })
\end{array}
$$

The presence of contact resistance between the sample and the fixture along with the upper frequency limitations due to higher order resonances are the main disadvantages of this method. However, the straightforward methodology employed to determine SE in the near-field scenario makes this method one of the most preferred for the EMI applications.

\section{Rectangular Waveguide Method}

Wilson et al. proposed that rectangular waveguides operating in $\mathrm{TE}_{10}$ mode could replace the coaxial transmission lines to determine the SE of a material. For this technique, the material had to be shaped according to the waveguide dimensions just as is in the case of the coaxial transmission line explained above. The mathematical aspect of this technique can be understood by first considering the SE of a rectangular panel of thickness $d$ for TEM wave, given as:

$$
\mathrm{SE}=\left|\frac{\left(\eta_{0}+\eta_{s}\right)^{2}}{4 \eta_{0} \eta_{s}}\right| \times\left|1-M e^{-2 \gamma d}\right|\left|e^{d \gamma}\right|
$$

where

$$
M=\left(\frac{\eta_{0}-\eta_{s}}{\eta_{0}+\eta_{s}}\right)^{2}
$$

where $\eta_{0}$ and $\eta_{s}$ are the intrinsic impedances of the free space and shield, respectively, while $\gamma$ denotes the propagation constant inside the shield. Since a rectangular waveguide does not support TEM wave mode, (12) must be modified accordingly. For a wave propagating in $\mathrm{TE}_{10}$ mode in a waveguide with the dimensions of the longer and shorter edge denoted by $a$ and $b$, respectively, then the shielding effect of the panel is expressed as ${ }^{100}$ :

$$
\mathrm{SE}=\left|\frac{\left(\gamma+j \beta_{0}\right)^{2}}{j 4 \beta_{0} \gamma}\right| \times\left|1-M^{\prime} e^{-2 \gamma d}\right|\left|e^{d \gamma}\right|
$$

where,

$$
M^{\prime}=\left(\frac{\gamma-j \beta_{0}}{\gamma+j \beta_{0}}\right)^{2}
$$

where $\beta_{0}$ is the propagation constant in the free space. One of the highlights of using this technique is that contact resistance does not play any significant role in the computations as reflection and transmission characteristics are considered unlike in the coaxial transmission line methods. The error arising due to the gap between the sample and the walls can be easily eradicated using air-gap error correction techniques that are already available in the literature. Therefore, the need for an absolutely perfect contact between the sample and the waveguide is more relaxed in this method as compared to the transmission line methods. Also, depending on the size of the waveguide, the EMI SE of a material could be analyzed over a broad spectrum of frequency. The aperture dimensions of commonly used waveguides for various microwave frequency bands are shown in Table II. The main disadvantage of using this technique is that a free-space wave (TEM mode) cannot be utilized, so the results obtained are not closely related to the far-field scenarios. ${ }^{96}$

\section{Nested Reverberation Chamber Method}

This method involves a setup that consists of a smaller reverberation chamber with a window on one of the walls placed inside a bigger reverberation chamber. The window of the smaller reverberation chamber is covered by the sample such that one side of the sample lies inside the smaller chamber while the other side faces the outer chamber. The outer chamber usually consists of one transmitting antenna and one receiving antenna. The smaller chamber consists of one receiving antenna as shown in Fig. 17. Both chambers are equipped with movable stirrers. The stirrers help in creating a near isotropic environment within the chamber. the EMI SE of the sample is given by ${ }^{101}$ :

$$
\mathrm{SE}(\mathrm{dB})=-10 \log \left(\frac{\bar{P}_{\text {inner }}}{\bar{P}_{\text {outer }}}\right)+\mathrm{CF}
$$

where $\bar{P}_{\text {inner }}$ and $\bar{P}_{\text {outer }}$ denote the power received in the inner and outer chamber, respectively. $\mathrm{CF}$ is known as the correction factor or loss factor or testfixture calibration factor that basically accounts for 
Table II. Aperture dimensions of waveguides for various microwave bands

\begin{tabular}{lc}
\hline Microwave band (frequency range) & Aperture dimension in inches (in mm) \\
\cline { 1 - 2 } $\mathrm{UH}^{\mathrm{a}}(0.3 \mathrm{GHz}-1 \mathrm{GHz})$ & $11.5 \times 5.75(292.1 \times 146.05)$ to $23 \times 11.5(584.2 \times 292.1)$ \\
$\mathrm{L}(1 \mathrm{GHz}-2 \mathrm{GHz})$ & $6.5 \times 3.25(165.1 \times 82.55)$ \\
$\mathrm{S}(2 \mathrm{GHz}-4 \mathrm{GHz})$ & $2.84 \times 1.34(72.14 \times 34.04)$ \\
$\mathrm{C}(4 \mathrm{GHz}-8 \mathrm{GHz})$ & $1.872 \times 0.872(47.55 \times 22.15)$ \\
$\mathrm{X}(8 \mathrm{GHz}-12 \mathrm{GHz})$ & $0.9 \times 0.4(22.86 \times 10.16)$ \\
$\mathrm{Ku}(12 \mathrm{GHz}-18 \mathrm{GHz})$ & $0.622 \times 0.311(15.8 \times 7.9)$ \\
$\mathrm{K}(18 \mathrm{GHz}-27 \mathrm{GHz})$ & $0.42 \times 0.17(10.67 \times 4.32)$ \\
$\mathrm{Ka}(27 \mathrm{GHz}-40 \mathrm{GHz})$ & $0.28 \times 0.14(7.11 \times 3.56)$ \\
\hline
\end{tabular}

The aperture dimensions of other commercially available waveguides can be found in: https://www.everythingrf.com/tech-resources/wa veguides-sizes.

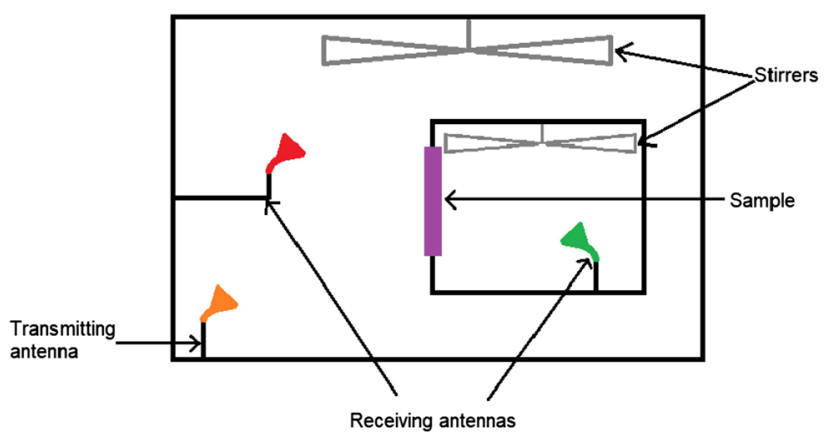

Fig. 17. SE measurement setup using a nested reverberation chamber (modified and adapted from the data available in ${ }^{101}$ ).

the coupling inside the inner chamber. Mathematically it is represented as ${ }^{102}$ :

$$
\mathrm{CF}=-10 \log \left(\frac{\bar{P}_{r, \text { inner }}}{\bar{P}_{t, \text { inner }}}\right)
$$

where $\bar{P}_{r \text {,inner }}$ and $\bar{P}_{t \text {,inner }}$ denote the received power inside the inner chamber and the power radiated by the transmitting antenna placed inside the inner chamber with the sample present at the aperture. Although the inclusion of CF enhances the reliability of this method, the accuracy of this method still remains a concern. In the absence of a sample the $\mathrm{SE}$ should be $0 \mathrm{~dB}$; however, (13) and (14) do not corroborate this fact. Holloway et al. proposed to take into account the effective cross sections, $\sigma_{\mathrm{u}}$ and $\sigma_{1}$, of the aperture both in the absence and presence of the sample, respectively, in order to overcome this problem. According to the proposed method ${ }^{102}$ :

$$
\mathrm{SE}=-10 \log \left(\frac{\sigma_{\mathrm{l}}}{\sigma_{\mathrm{u}}}\right)
$$

where

$$
\sigma_{l}=\frac{2 \pi V S_{l, \text { inner }}}{\lambda Q_{l, \text { inner }} S_{l, \text { outer }}}
$$

$$
\sigma_{u}=\frac{2 \pi V S_{u, \text { inner }}}{\lambda Q_{u, \text { inner }} S_{l, \text { outer }}}
$$

$V$ represents the inner chamber's volume, $S_{l, \text { inner }}$ and $S_{u \text {,inner }}$ denotes power density associated with inner chamber in loaded and unloaded cases respectively, whereas $S_{l, \text { outer }}$ and $S_{u, \text { outer }}$ represent the power density associated with outer chamber in the loaded and unloaded conditions, respectively. $Q_{u, \text { inner }}$ and $Q_{l \text {,inner }}$ represent the quality factor of the inner chamber in the unloaded and loaded scenarios, respectively. The biggest advantage of this method is that it can test the shielding capability of a sample in real-world conditions that are simulated inside the chamber. This is possible due to the flexibility in the orientation and polarization configurations of the antennas. The stirrers too can change the field distribution in the chamber to match with the fields present in the free-space environment. ${ }^{101}$

\section{Shielded Box Method}

This is a simple method usually done for comparative testing of materials. This method involves the use of a metallic box with a small port mounted over one of the walls. An antenna acting as a receiver is fixed inside the box, while another antenna acting as a transmitter stays outside, as shown in Fig. 18. The received power is first measured with the port left unloaded or open. Later, the port is covered with the sample and again the received power is recorded with the help of a VNA. ${ }^{103}$

This method is very simple to carry out; however, the maximum frequency for which it gives accurate results is $500 \mathrm{MHz}$ only. Therefore, this method is not suitable for high frequency measurements.

\section{Shielded Room Method}

In order to overcome the shortcomings of shielded box method, shielded room method was developed. 


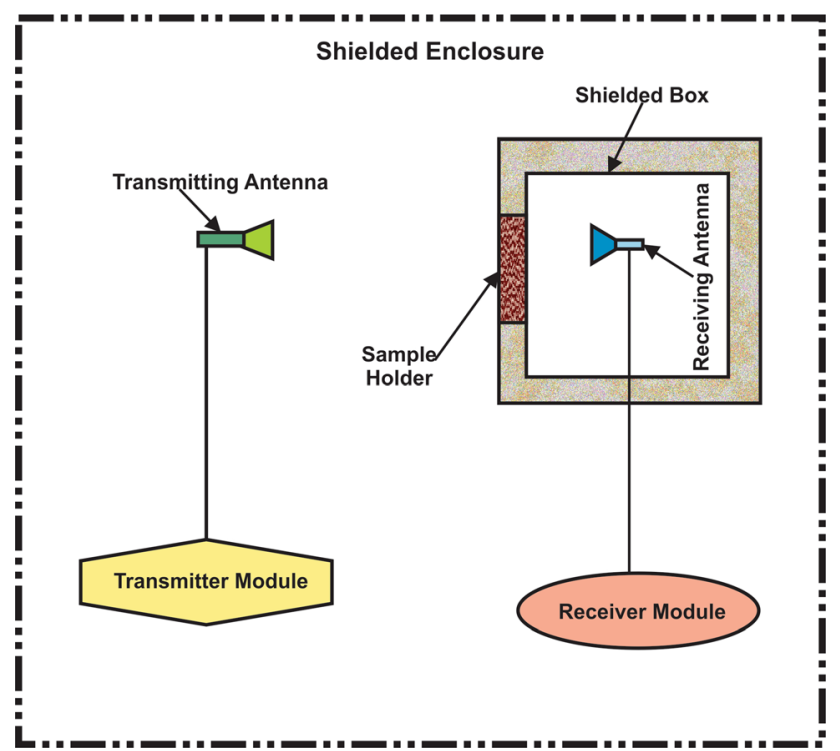

Fig. 18. Shielding effectiveness measurement setup using a shielded box (modified and redrawn using the data available in ${ }^{104}$ ).

According to this method, the sample and the antennas are placed inside anechoic chamber while the back-end components such as receiver, signal generator, and power supply are placed in multiple shielded rooms or enclosures to avoid any EMI associated with them. The sample size is greatly increased to size of about $2.5 \mathrm{~m}^{2}$. The working principle is similar to the shielded box method. ${ }^{1,104}$

This method is far more reliable and repeatable as compared to shielded box method. The only drawback is that this method requires a very large sample to be tested. Fabricating such a large sample is usually a longer and more expensive process.

\section{Free-Space Method}

This method involved two horn antennas typically placed facing each other with the MUT placed in between. The shielding effectiveness is then measured using (2). This method does not account for diffracted and reflected fields; therefore, the measured data is then usually treated with a timedomain gating algorithm to get accurate results. ${ }^{105}$ Dvurechenskaya et al. proposed a time domain method to extract the shielding effectiveness of a textile using the free-space method. According to the method proposed in the paper, the first step is to determine the time domain counterpart $\left\{s_{21}\right\}$ of the measured frequency domain transmission coefficient $S_{21}$ using:

$$
\left\{s_{21}\right\}=\operatorname{IDFT}\left\{W(f) S_{21}(f)\right\}
$$

where $W(f)$ is the frequency window used to suppress side lobes. $S_{21}$ is then applied to (18) in either bandpass mode (center frequency,$f>0$ ) or in lowpass mode (center frequency, $f \simeq 0$ ). Then, using a discrete Fourier transform, $\left\{s_{21}\right\}$ is transformed back to frequency domain as:

$$
\left\{S_{21, T}\right\}=D F T\left\{s_{21} w(f)\right\}
$$

where $w(f)$ is the time gating window chosen to only select the part of $s_{21}$ related to straight line and reject the diffracted and other unwanted components. The shielding effectiveness is then calculated as:

$$
S E(d B)=20 \log \frac{\left|S_{21, \mathrm{~ns}}\right|}{\left|S_{21}\right|}
$$

where $S_{21, n s}$ is the transmission parameter measured without the sample and processed according to the proposed algorithm.

The frequency range and sample shape and size used for each of the discussed techniques are summarized in Table III.

This section would be incomplete without mentioning the Nicholson-Ross-Weir (NRW) method, an indirect method used to mathematically determine the EMI SE of a material directly from its Sparameters as well as its complex dielectric parameters, i.e., permittivity $\left(\epsilon_{m}\right)$ and permeability $\left(\mu_{m}\right)$. The techniques mentioned above to determine the shielding effectiveness of a specimen are generally followed by the NRW method to compare the measured EMI SE with that of the computed one. ${ }^{106}$ This method is also used to measure $\epsilon_{m}$ and $\mu_{m}$ of the shielding material, thereby providing in-depth information about its dielectric profile. The determination of these properties using the NRW method are based on the following equations ${ }^{107}$ :

$$
S_{11}=\frac{R\left(1-T^{2}\right)}{\left(1-R^{2} T^{2}\right)}
$$

and

$$
S_{21}=\frac{T\left(1-R^{2}\right)}{\left(1-R^{2} T^{2}\right)}
$$

where $|R|<1$ and is given by,

$$
R=\frac{S_{11}^{2}-S_{21}^{2}+1}{2 S_{11}} \pm \sqrt{\frac{S_{11}^{2}-S_{21}^{2}+1}{2 S_{11}}-1}
$$

By substituting this value of $R$ in (21) or (22), $T$ can be obtained as:

$$
T=\frac{S_{11}+S_{21}-R}{1-\left(S_{11}-S_{21}\right) R}
$$

According to the NRW method, $\mu_{m}$ is expressed as: 
Table III. Sample geometry, frequency range and measured parameters associated with various EMI SE measurement techniques

\begin{tabular}{|c|c|c|c|}
\hline Technique & Sample geometry & Frequency range & Parameters measured \\
\hline $\begin{array}{l}\text { Coaxial Trans- } \\
\text { mission Line } \\
\text { Method }\end{array}$ & $\begin{array}{c}\text { Torus and disc shaped sample } \\
\text { matching the dimensions of } \\
\text { inner and outer flanges } \\
\text { respectively }\end{array}$ & $\begin{array}{c}30 \mathrm{MHz}-1.5 \mathrm{GHz} \text { but efforts } \\
\text { have been made to enhance } \\
\text { the upper frequency limit to } \\
18 \mathrm{GHz}\end{array}$ & $\begin{array}{c}\text { Transmission coefficient for loaded and } \\
\text { unloaded cases }\end{array}$ \\
\hline $\begin{array}{l}\text { Dual TEM Cell } \\
\text { Method }\end{array}$ & $\begin{array}{c}\text { Rectangular slab shaped } \\
\text { sample matching the } \\
\text { dimensions of the } \\
\text { rectangular slot }\end{array}$ & $1 \mathrm{MHz}-1 \mathrm{GHz}$ & $\begin{array}{c}\text { Transmission coefficients for loaded } \\
\text { and unloaded cases }\end{array}$ \\
\hline $\begin{array}{l}\text { Rectangular } \\
\text { Waveguide } \\
\text { Method }\end{array}$ & $\begin{array}{c}\text { Rectangular plate matching } \\
\text { the dimensions of the } \\
\text { waveguide }\end{array}$ & $\begin{array}{l}\text { Broad frequency range } \\
\text { depending on waveguide } \\
\text { dimension }\end{array}$ & $\begin{array}{l}\text { Intrinsic impedance of the shielding } \\
\text { material and the propagation } \\
\text { constant inside it }\end{array}$ \\
\hline $\begin{array}{l}\text { Nested Rever- } \\
\text { beration } \\
\text { Chamber } \\
\text { Method }\end{array}$ & $\begin{array}{c}\text { Samples with both electrically } \\
\text { large and electrically small } \\
\text { geometries }\end{array}$ & Depends on the sample size & $\begin{array}{c}\text { Received and transmitted powers of } \\
\text { both antennas as well as the } \\
\text { effective cross sections of the } \\
\text { aperture in the loaded and unloaded } \\
\text { cases }\end{array}$ \\
\hline $\begin{array}{l}\text { Shielded Room } \\
\text { Method }\end{array}$ & $\begin{array}{l}\text { Very large rectangular- or } \\
\text { circular-shaped samples } \\
\text { with area of } 2.5 \mathrm{~m}^{2}\end{array}$ & $\begin{array}{c}\text { Up to } 1 \mathrm{GHz} \text { but efforts have } \\
\text { been made to increase } \\
\text { beyond } 10 \mathrm{GHz}\end{array}$ & $\begin{array}{c}\text { Received power for loaded and } \\
\text { unloaded cases }\end{array}$ \\
\hline $\begin{array}{l}\text { Free-Space } \\
\text { Method }\end{array}$ & Arbitrary shape & $\begin{array}{l}\text { No restriction; depends on the } \\
\text { frequency limit of the VNA } \\
\text { used }\end{array}$ & $\begin{array}{c}\text { Transmission coefficients or power in } \\
\text { loaded and loaded cases }\end{array}$ \\
\hline
\end{tabular}

$$
\mu_{m}=\frac{1+R}{X(1-R)} \sqrt{\frac{\lambda_{0}^{2} \lambda_{m c}^{2}}{\lambda_{0}^{2}-\lambda_{m c}^{2}}}
$$

where $\lambda_{0}$ and $\lambda_{m c}$ denote free-space wavelength and the cut-off wavelength, respectively. Here, $X$ is expressed as ${ }^{108}$ :

$$
\frac{1}{X^{2}}=\left(\frac{\epsilon_{m} \mu_{m}}{\lambda_{0}^{2}}-\frac{1}{\lambda_{m c}^{2}}\right)=-\left[\frac{1}{2 \pi L} \ln \left(\frac{1}{T}\right)\right]^{2}
$$

where $L$ is the sample length. On rearranging (26) $\left(\epsilon_{m}\right)$ can be determined using the following expression:

$$
\epsilon_{m}=\frac{\lambda_{0}^{2}}{\mu_{m}}\left(\frac{1}{\lambda_{m c}^{2}}-\left[\frac{1}{2 \pi L} \ln \left(\frac{1}{T}\right)\right]^{2}\right)
$$

The shielding effectiveness of a material can be expressed as, ${ }^{106,109}$

$$
|S E(d B)|=10 \log (R e f)+10 \log (A b r)+10 \log (M E)
$$

where Ref represents reflection loss, Abr represents absorption loss and ME loss due to multipath effect. Multipath reflections become insignificant at frequencies greater than $1 \mathrm{GHz}$. These losses are computed using the following equations ${ }^{107,110}$ :

$$
\begin{gathered}
R e f=1-S_{11}^{2} \\
A b r=\frac{S_{21}^{2}}{1-S_{11}^{2}} \\
M E=1-10^{-\frac{-8.68 d \sqrt{\frac{\sigma_{m \omega \mu}}{2}}}{10}}
\end{gathered}
$$

where $\sigma_{m}$ is the conductivity and $d$ denotes the thickness of the shield. On substituting (29), (30) and (31) in (28), the shielding effectiveness of a material can be obtained. However, for some particular conditions, shielding effectiveness can be calculated in a more straightforward fashion. For instance, for electrically thin samples (thickness is much less than skin depth, $\delta$ ), SE can be calculated using:

$$
S E=20 \log \left(1+\frac{1}{2} Z_{0} d \sigma_{m}\right)
$$

where $Z_{0}$ is the free-space impedance. For electrically thick samples, however, the shielding effectiveness can be obtained using ${ }^{109}$ :

$$
S E=10 \log \left(\frac{\sigma_{m}}{16 \omega \epsilon_{0} \mu_{m}}\right)+10 \log \left(e^{d / \delta}\right)^{2}
$$


Therefore,

$$
S E=10 \log \left(\frac{\sigma_{m}}{16 \omega \epsilon_{0} \mu_{m}} e^{2 d / \delta}\right)
$$

where $\epsilon_{0}$ is the permittivity of the free space.

As mentioned, by using the NRW method, the shielding effectiveness as well as other properties of the material are also determined. This helps in understanding the shielding mechanism of the material that can be used to design and simulate the EMI shield.

Apart from the above EMI SE measurement techniques, the shielding effectiveness of the material depends on its structure and the way it is supposed to be used as a protective gear for the equipment, against EMI radiation. ${ }^{111}$ Some of the most popular electromagnetic shielding structures are listed as following:

1. Faraday Cage

2. EMI Shielding Gaskets

3. Electromagnetic Absorbers

4. EMI Shielding Textiles

1. Faraday Cage One of the first electromagnetic shields was a Faraday cage. ${ }^{112}$ A Faraday cage is a hollow structure with a metallic screen or wire mesh as walls that electrically separate the equipment present inside to the one placed outside the cage. ${ }^{112,113}$ For an electric field incident on the walls of a Faraday cage, the electrons in the walls mobilize in a manner that cancels the electric field on the other side of the wall. ${ }^{114}$ Although this device was invented in 1836 by Michael Faraday, it has maintained relevance today in EMI shielding applications. ${ }^{114-119}$ One of the biggest disadvantages of using Faraday cages for EMI reduction is that these structures provide less shielding efficiency. ${ }^{116}$

2. EMI Shielding Gaskets In applications where foldable shields are employed, the gap between each panel of the shield may act as a front for EMI radiation. Under such conditions, the joints and hinges should be properly secured so as to block any potential emission. To ensure that EMI shielding gaskets are used. These structures mainly ensure that the current flow throughout the shield remains unobstructed and continuous. ${ }^{120}$ IEEE Standard 1302 and SAE ARP 1705 rev. A standard (2006) are popular standards that layout the method and conditions to determine the shielding effectiveness of EMI shielding gaskets. ${ }^{120,121}$ According to the former standard, there are two ways that can lead to the measurement of SE of gaskets. The first method is known as aperture attenuation in which the transmission line model of the gasket is developed and the intrinsic impedance on both sides of the shield is calculated. The SE of a gasket is then given by ${ }^{111,120}$

$$
S E=20 \log \left(\frac{\eta_{\text {free-space }}}{\eta_{\text {gasket }}}\right)
$$

where $\eta_{\text {free-space }}$ and $\eta_{\text {gasket }}$ are the intrinsic impedance of the free space and gasket, respectively. This method is useful to take measurements from dc to $18 \mathrm{GHz}$. The second method is known as current injection in which the transfer impedance $Z_{\text {transfer }}$ is utilized to measure the SE of the gasket. Transfer impedance is the ratio of the voltage drop $V_{\text {drop }}$, across the hinge or seam that holds the gasket to the current density per unit length $J$ on the side of the gasket that faces the incoming incident field, i.e.:

$$
Z_{\text {transfer }}=\frac{V_{d r o p}}{J}
$$

The SE of the gasket is then computed using the expression:

$$
S E=20 \log \left|\frac{d \cdot \eta_{\text {free-space }}}{2 Z_{\text {transfer }}}\right|
$$

where $d$ is the thickness of the gasket. This method yields accurate results up to $2 \mathrm{GHz}$. One of the major drawbacks of this test is that the SE of the gasket is not measured directly. Therefore, the probability for error in the computation is high.

3. Electromagnetic Absorbers Electromagnetic absorbers have been in use for a number of applications including health monitoring systems, defense, radar cross section reduction etc. ${ }^{122}$ They are extensively used in EMI/EMC technology too. They are one of the main components in the EMI measurement setups including anechoic chambers and GTEM cells. $^{21,25}$ The most important parameter that is considered while designing and analyzing these absorbers is the reflection coefficient. In simple terms, reflection loss is nothing but the ratio of the field strength reflected from the shield to the field strength incident on it. ${ }^{111}$ If a transmission line equivalent model is used to analyze the performance of an absorber then the reflection coefficient $R$, is given by ${ }^{123}$ :

$$
R=20 \log \left(\frac{Z_{I}-1}{Z_{I}+1}\right)
$$

$Z_{I}$, normalized input impedance is given by:

$$
Z_{I}=\sqrt{\frac{\mu}{\epsilon}} \tanh \left(j \frac{2 \pi f t}{c} \sqrt{\mu \epsilon}\right)
$$

where $\mu$ and $\epsilon$ are the permeability and permittivity of the absorber, $t$ is the thickness of the absorber, $c$ is the velocity of light and $f$ is the frequency. The absorption coefficient of the absorber is given by ${ }^{124}$ : 


$$
A=\frac{1}{2}\left(\sigma+\omega \epsilon_{\circ} \epsilon_{m}\right) E^{2}+\frac{1}{2} \omega \mu_{\circ} \mu_{m} H^{2}
$$

where $\sigma$ is the conductivity of the absorber, $\omega$ is the angular velocity of EM wave, $\epsilon_{\circ}$ and $\mu_{\circ}$ are the permittivity and permeability of the free space while $\epsilon_{m}$ and $\mu_{m}$ are the permittivity and permeability of the material. The transmission coefficient $T$, of the absorber is then given by ${ }^{124}$ :

$$
T=1-R-A
$$

Materials such as ferrites, ${ }^{125}$ metamaterials, ${ }^{122,126}$ and carbon-nano tubes ${ }^{127}$ are often used to develop EM absorbers. Jafarian et al. presented an X-band microwave absorber for EMI shielding applications. The absorber consisted of $\mathrm{SrFe}_{10} \mathrm{Al}_{2} \mathrm{O}_{19} / \mathrm{MWCNT}$ / polypyrrole and $\mathrm{Ni}_{0.5} \mathrm{Zn}_{0.5} \mathrm{Fe}_{2} \mathrm{O}_{4} / \mathrm{MWCNTs} /$ polypyrrole composites. The authors computed the SE of the absorber using the formula ${ }^{128}$ :

$$
S E_{\text {total }}=S E_{\text {ref }}+S E_{\text {abs }}
$$

where

$$
S E_{r e f}=10 \log \frac{1}{1-\left|S_{11}\right|^{2}}
$$

and

$$
S E_{a b s}=10 \log \frac{1-\left|S_{11}\right|^{2}}{\left|S_{21}\right|^{2}}
$$

$S E_{r e f}$ is the shielding effectiveness due to reflection and $S E_{a b s}$ is the shielding effectiveness due to absorption. The thickness of the presented absorber was $3 \mathrm{~mm}$ and it could achieve a reflection coefficient of $-34.5 \mathrm{~dB}$ with matching frequency at $10.8 \mathrm{GHz}$ and bandwidth of $3.05 \mathrm{GHz}$. Another parameter of interest regarding the EMI shielding behavior of the absorbers is known as specific EMI shielding effectiveness (SSE). It is given as:

$$
S S E=\frac{S E}{\text { density }}
$$

This parameter is useful to describe the shielding characteristics of absorbers that are considered to be used in bulk, e.g., in aerospace applications or building materials. Yang et al. developed a carbon nanotube-polysterene foam composite with SSE $33.1 \mathrm{~dB} \mathrm{~cm}^{3} \mathrm{~g}^{-1}$. ${ }^{129,130}$

Beeharry et al. proposed a radar absorber to reduce EMI in radomes. The absorber consisted of a frequency selective surface (FSS) layer resting on top of two layers of different substrates separated by an air gap. The thickness of the absorber was 1/7.2 times the operating wavelength. The absorber operated over a frequency ranging from $4.8 \mathrm{GHz}$ to $11.1 \mathrm{GHz}{ }^{131}$ Apart from these few mentioned examples/materials, several other absorbing materials have been developed by various research groups to enhance EMI shielding effectiveness of a system as shown in Table IV

4. EMI Shielding Textiles With the proliferation of electronic devices for biomedical applications such as pacemakers and implantable cardioverter defibrillator (ICD), the need to shield them from external EMI in the environment has also gained significant attention from the scientific community. EMI shielding textiles are proving to be the best method to protect these devices from unwanted noise interferences. The advantages of these materials is that they are relatively easy to develop, are cost effective, light and flexible. ${ }^{152}$ Materials such as composite yarns made up of a mixture of fibers of steel, copper, etc., nonwoven fabric, or conductive polymers are usually used to develop EMI shielding fabrics. ${ }^{153}$ Koprowska et al. prepared a textile material that was capable of exhibiting an EMI shielding effect using plasma metallization process in which an SE of more than $50 \mathrm{~dB}$ was achieved. The textile shield consisted of a metallic film deposited over polypropylene nonwovens. The authors made use of the ASTM D4935-99 method to carry out the testing. ${ }^{152}$ Tian et al. created a multilayered cotton-based fabric consisting of alternate layers of poly(sodium 4styrenesulfonate) (PSS) as a polyanion and chitosan-graphene layer deposited over a pure cotton fabric. ${ }^{154}$ The maximum conductivity of the material was determined to be $1.67 \times 10^{3} \mathrm{~S} / \mathrm{m}$ while the SE was measured to be more than $30 \mathrm{~dB}$. Tan et al. were able to device a technique to fabricate silver-coated cotton fiber $(\mathrm{Ag} @ \mathrm{CF})$ in nonwoven fabrics. The group was able to achieve ultra-high EMI SE of about $71 \mathrm{~dB}$ when $1.61 \mathrm{vol} \% \mathrm{Ag}$ was deposited for $10 \mathrm{~s}$ on the surface of cotton fibers and $111 \mathrm{~dB}$ when $\mathrm{Ag}$ was deposited for $3 \mathrm{~min}{ }^{155}$ Most shielding fabrics rely on the reflection mechanism more than they rely on the absorbing mechanism. These reflections, despite protecting the shielded equipment, allow harmful radiation to travel elsewhere in the free space and pose serious threats to nearby equipment. If absorbing materials are used to develop such fabrics then challenges such as cost and thickness are encountered. Keeping this issue in mind along with the corrosive nature of metals used in these fabrics, Geng et al. recently proposed $\mathrm{Ti}_{3} \mathrm{C}_{2} \mathrm{~T}_{x}$ coated cotton fabric as a promising solution. The fabricated specimen was able to achieve average shielding effectiveness of $48.9 \mathrm{~dB}$ within the frequency range of $2-18 \mathrm{GHz}{ }^{156}$

\section{EMI Filters}

The conducted emission noise generally comprises of two noise components, differential mode (DM) and common mode (CM). DM noise is generated due to the normal flow of current in the loops formed by 


\section{Material}

$75 \%$ Fly Ash $+20 \%$ Silica Fume $+0.6 \%$ multi-wall carbon nanotube (MWNT)

Reinforced concrete composites (RCC) with a 3 wt.\% carbon nanotube

$40 \%$ electric arc furnace slag (EAFS) in mortar

Poly(acrylonitrile-co-butadiene-co-styrene) (ABS) with CNT filler (5\% and 15\%)

Poly(acrylonitrile-co-butadiene-co-styrene) (ABS) with carbon black (CB) filler (5\% and 15\%)

Cellulose/Carbon Fiber $(L / D=300)$ composite foam

Polypropylene (PP)/polyethylene (PE) blends filled with 5 vol.\% graphene nano-platelets:carbon nanotube (GNP:CNT) hybrid nanofiller

Carbon fiber stitched with Dyneema T90 thread

Carbon fiber reinforced multilayered pyrocarbon-silicon carbide $\left((\mathrm{PyC}-\mathrm{SiC})_{n}\right)$ matrix $\left(\mathrm{C} /(\mathrm{PyC}-\mathrm{SiC})_{n}\right)$ composite

Polypyrrole (PPy)/polydopamine (PDA)/silver nanowire $(\mathrm{AgNW})$ composites

Polyaniline/cobalt-nickel (PANI/co-Ni) coatings deposited over lyocell fabrics

Carbon fiber deposited with magnetic material (Nickel)

Mg-Y-Zr-Nd alloy

Highly flexible and ultra-thin Ni-plated nonwoven carbon fabric/polycarbonate film

Ferromagnetic nanoparticles deposited over macroporous epoxy-carbon fiber structures with a sacrificial polymeric mesh

Silicone rubber filled with 240 phr Ag-coated cenosphere particles

Nitrogen doped cobalt particle-embedded carbonaceous nanostructures

Expanded polystyrene (EPS) particles were coated with copper

$\mathrm{Cu} / \mathrm{AgNW}$ s/PI film

Fly ash cenospheres (FACs) + AZ91Mg alloy

11 wt.\% Carbon nanocoils-11 wt.\% CNT, polyurethane 78 wt. $\%$

\begin{tabular}{|c|c|c|c|}
\hline $\begin{array}{c}\text { Shielding effective- } \\
\text { ness (dB) }\end{array}$ & $\begin{array}{l}\text { Frequency } \\
\quad(\mathbf{G H z})\end{array}$ & $\begin{array}{c}\text { Thickness } \\
\text { (mm) }\end{array}$ & References \\
\hline $8-57.1$ & $1-18$ & 10 & 132 \\
\hline 80 & 2.6 & 300 & 133 \\
\hline 15-22 & $3-18$ & 20 & 134 \\
\hline 44 and 83 & $8-12.4$ & 3 & 135 \\
\hline 9 and 34 & $8-12.4$ & 3 & 135 \\
\hline 60 & $0.03-1.5$ & - & 136 \\
\hline 25 & 12 & 1 & 137 \\
\hline $\begin{array}{c}43.7 \text { (Axial direction) } \\
\text { and } 64.6 \text { (Normal } \\
\text { direction) }\end{array}$ & $8-12$ & 4 & 138 \\
\hline 42 & $8.2-12.4$ & 2 & 139 \\
\hline 48.4 & 8 & $>0.095$ & 140 \\
\hline $33.95-46.22$ & $8.2-12.4$ & - & 141 \\
\hline $40-50$ & $12-18$ & 0.4 & 142 \\
\hline $\begin{array}{c}78-110 \\
72.7\end{array}$ & $\begin{array}{c}0.4-1.4 \\
0.03-1.5\end{array}$ & $\begin{array}{c}2 \\
1.075 \times 10^{-3}\end{array}$ & $\begin{array}{l}143 \\
144\end{array}$ \\
\hline 45 & $12-18$ & 1.4 & 145 \\
\hline$>80$ & $0.1-1.5$ & 2.75 & 146 \\
\hline 33 & 18 & 4 & 147 \\
\hline $14-39$ & $80-110$ & 60 & 148 \\
\hline $55-56$ & $0.1-1.5$ & 0.01 & 149 \\
\hline $75-90$ & $0.03-1.5$ & 3 & 150 \\
\hline 20 & $0.5-3$ & 3 & 151 \\
\hline
\end{tabular}

various components in the circuit. These loops might start behaving like small loop antennas which radiate EMI noise. CM noise is generated due to parasitic impedances induced in the circuit due to undesired voltage drops. This happens when the current gets leaked via a stray capacitance or inductance and returns back to the power supply line. ${ }^{157}$ If these noise signals reach the output terminal of the circuit, then they get radiated into their environment posing a threat to the nearby equipment. A common way of countering the generated CM and DM noises is to filter them out of the system using EMI filters. ${ }^{158} \mathrm{CM}$ and DM noise signals require different techniques to be filtered; therefore, usually a noise separator is used to separate these two unwanted signals. After their separation, filters are introduced in the circuit. ${ }^{159}$ One of the earliest papers that laid down the theory of miniature EMI filters was first proposed in 1964 by Schlicke where he suggested that thin film-based ceramic low-pass filters were preferred to mitigate EMI problems over their counterparts as these filters were easy to fabricate and showed better response at high frequencies. ${ }^{160}$ Since then much effort has been put into developing EMI filters that can combat the adversities posed by EMI noises. ${ }^{161-166}$ In 2006, Nan et al. developed an EMI filter that consisted of a large high permeability loop (to suppress CM noise) and two smaller low permeability loops (to suppress DM noises) 
arranged transversely along the diameter of the larger loop. The filter was capable of suppressing both CM and DM noise. ${ }^{167}$ Another filter aimed at reducing both types of noise signals was proposed by Maillet et al. in 2010. The filter was developed to be used to reduce EMI in motor drives that were fed by a dc input. This filter consisted of two DM capacitors and one CM capacitor to bypass the noise due to their low impedance along with one high impedance CM choke with ferrite core to filter out the EMI noise. The authors were able to reduce the interfering noise by $8 \mathrm{~dB}$ to $18 \mathrm{~dB}$ using this filter. ${ }^{168}$ Since conventional EMI filters are quite bulky, hybrid filters are used to reduce the payload. Hybrid filters comprise of an active filter (containing amplifiers and other active devices) and a smaller passive filter. ${ }^{169-171}$ Goswami et al. developed a DM active filter for boost power factor correction AC/DC converter. The proposed filter was able to reduce the EMI noise by $30-35 \mathrm{~dB} .^{171}$ Metallized film capacitors are also used to filter out unwanted EMI noise. These capacitors consist of thin layer of metal as electrodes separated by a sheet of dielectric. Two of the most commonly used dielectric materials for these capacitors are polypropylene (PP) and polyethylene terephthalate (PET) while the metallic electrodes could be a thin film (thickness of the order of nanometers) of aluminium or zinc deposited over the dielectric or it could be made of Babbitt metal (a combination of zinc and tin) sprayed over the wound capacitor roll in order to complete the circuit. ${ }^{172}$ The unique property of these capacitors that makes them favorable for EMI filtering applications is that they are able to withstand high voltages and exhibit self-healing property in the event of voltage breakdown.

The main advantage of using a filter for EMI reduction is that they are easy to design, more cost effective for smaller systems and easier to implement. The biggest disadvantage of using filters is that interferences whose characteristics (frequency, mode of transmission etc.) are different than the characteristics of the system are detected and removed. However, in case the interference has similar nature to the signals flowing in the circuit it could possible survive the filtering process and continue to cause harm to the system. ${ }^{111}$

\section{Circuit Topology}

If the components of the circuit are not arranged optimally then loop inductances, parasitic capacitances etc. can be generated giving rise to spurious noise signals. Therefore, it is extremely important to assign a proper location to each and every component within the electronic system. ${ }^{173}$ Bhargav et al. could reduce the EMI of DC-DC buck converter after modifying the layout of the PCB by optimizing the locations of FET, decoupling capacitor and vias. ${ }^{174}$ Similarly, Lee et al. demonstrated the EMI reduction in PCB by modifying the area and the location of the ground plane. ${ }^{175}$

\section{Spread Spectrum Technique}

Vidya et al. used a spread spectrum clock generator to reduce EMI in digital circuits. The authors focused on the clock used in these circuits as they are the major contributors of noise signal generation due to their high frequency. In the spread spectrum, the energy accumulated in the narrowband is spread over a wider bandwidth using frequency modulation. ${ }^{176}$ Consequently, the value of peak energy is reduced which leads to low probability of EMI generation. In the mentioned paper, the authors used delta-sigma modulation to reconfigure the clock signal. ${ }^{177}$

\section{CONCLUSION}

This review paper starts with an elaborate discussion on the meaning and sources of EMI followed by its historical background. The techniques generally used to measure the EMI under two broad categories, namely, emission testing and immunity testing, are also presented in detail. There are two types of emissions considered for EMI measurements, namely, radiated emission and conducted emission. Radiated emission testing is done in the open-area test-site setup or in chambers such as anechoic chambers, GTEMs or reverberation chambers. Conducted emission testing is done to measure the EMI generated due to abrupt change in voltages and currents within the circuitry of the EUT. In order to do this, methods such as LISN, $1 \Omega$ method, probe method or TEM cell method is used. All these EMI measurement methods are explained elaborately and the relevant internationally accepted respective standards are mentioned in the text for further reading.

Apart from EMI measurement techniques mentioned above, this review also focuses on the general methods used to reduce the EMI due to an electronic device. These methods include the use of electromagnetic shields, EMI filters, changes in the circuit topology itself and the spread spectrum technique. Special attention is given to electromagnetic shielding as it is probably the most preferred EMI reduction technique. Various methods employed to measure the shielding effectiveness of materials are discussed theoretically as well as mathematically. The review paper presents the topic of EMI in totality by including both, the measurement techniques and the reduction techniques. Thus, it could be beneficial for both the established researcher and new researcher to get a good knowledge about the electromagnetic interference.

\section{ACKNOWLEDGMENTS}

This work was financially supported by University Grants Commission (UGC), Govt. of India under UGC-FRP (Faculty Recharge Program). 


\section{REFERENCES}

1. J.L.N. Violette, D.R.J. White, and M.F. Violette, Electromagnetic Compatibility Handbook (New York: Springer, 1987).

2. M.J. Horst, W.A. Serdijn, and A.C. Linnenbank, EMI-Resilient Amplifier Circuits (Berlin: Springer, 2013).

3. M. Shalaby, W. Saad, M. Shokair, and N.W. Messiha, Wirel. Pers. Commun. 96, 2223 (2017).

4. D. Morgan, A Handbook for EMC Testing and Measurement (London: IET, 1994).

5. B.R. Archambeault and J. Drewniak, PCB Design for RealWorld EMI Control (Berlin: Springer, 2013).

6. S.H. Voldman and E.S.D. Testing, From Components to Systems (New York: Wiley, 2016).

7. M.I. Montrose and E.M. Nakauchi, Testing for EMC Compliance: Approaches and Techniques (New York: Wiley, 2004)

8. D.G. Baker, Electromagnetic Compatibility: Analysis and Case Studies in Transportation (New York: Wiley, 2015).

9. A. Raveendran, M.T. Sebastian, and S. Raman, J. Electron. Mater. 48, 2601 (2019).

10. J.M. Thomassin, D. Vuluga, M. Alexandre, C. Jrme, I. Molenberg, I. Huynen, and C. Detrembleur, Polym. J. 53, 169 (2012).

11. X.C. Wang, Y.Y. Sun, J.H. Zhu, Y.H. Lou, and W.Z. Lu, IEEE Trans. Electromagn. Compat. 59, 996 (2017).

12. S. Wang, Y.Y. Maillet, F. Wang, D. Boroyevich, and R. Burgos, IEEE Trans. Power Electron. 25, 1034 (2010).

13. X. Chen, W. Chen, Y. Ren, L. Qiao, and X. Yang, in 2018 IEEE Energy Conversion Congress and Exposition (ECCE), pp. 4671-4674 (2018).

14. S. Maniktala, Switching Power Supplies A-Z, 2nd ed., ed. S. Maniktala (London: Newnes, 2012), p. 597.

15. L.A. Dina, P.M. Nicolae, I.D. Smarandescu, and V. Voicu, in 2017 International Conference on Electromechanical and Power Systems (SIELMEN), pp. 202-207 (2017).

16. P.T. Trakadas and C.N. Capsalis, IEEE Trans. Electromagn. Compat. 43, 29 (2001).

17. Z.N. Chen, D. Liu, H. Nakano, X. Qing, and T. Zwick, Handbook of Antenna Technologies (Singapore: Springer, 2016).

18. R.F. German and R. Calcavecchio, in 1980 IEEE International Symposium on Electromagnetic Compatibility, pp. 1-7 (1980).

19. P. Shen, Y. Qi, W. Yu, and F. Li, IEEE Trans. Electromagn. Compat. 59, 1708 (2017).

20. M. Ameya, S. Kurokawa, I. Watanabe, M. Yamaguchi, and R. Hasumi, in 10th International Symposium on Electromagnetic Compatibility, pp. 186-191 (2011).

21. M. Pospisilik, S. Kovar, and V. Kresalek, Data Brief 21, 234 (2018).

22. M.H. Nisanci, E.U. Kksille, Y. Cengizc, A. Orlandi, and A. Duffy, Expert Syst Appl. 38, 1689 (2011).

23. L.R. Arnaut, Wave Motion 51, 673 (2014).

24. P.C. Chen, K.Y. Yang, Y.H. Lin, W.S. Wang, T.Y. Wu, and R.B. Wu, IEEE Trans. Compon. Packag. Manuf. Technol. 7, 1852 (2017).

25. K. Malaric, J. Bartolic, and R. Malaric, Measurement 38, 219 (2005)

26. H.H. Park, H.B. Park, and H.S. Lee, IEEE Trans. Electromagn. Compat. 55, 257 (2013).

27. X. Wang and R. Vick, IEEE Electromagn. Compat. 6, 32 (2017).

28. X. Gao, D. Su, L. Zhai, and X. Zhang, Energy Proc. 88, 662 (2016).

29. J. Li, S. Li, S. Xing, and R. Kan, in 2009 3rd IEEE International Symposium on Microwave, Antenna, Propagation and EMC Technologies for Wireless Communications, pp. 378-380 (2009).

30. Z.M. Al-Daher, A. Nothofer, C. Christopoulos, and S. Greedy, in 2010 Loughborough Antennas \\& Propagation Conference, pp. 133-136 (2010).
31. B. Palczynska, in 2017 IEEE International Conference on Environment and Electrical Engineering and 2017 IEEE Industrial and Commercial Power Systems Europe (EEEIC /I \\& CPS Europe), pp. 1-6 (2017).

32. K.L. Chua, M.Z.M. Jenu, M.O. Wong, S.H. Ying, in 2013 Asia-Pacific Symposium on Electromagnetic Compatibility (APEMC), pp. 1-4 (2013).

33. D.A. Hill, Electromagnetic Fields in Cavities: Deterministic and Statistical Theories (New York: IEEE Press, 2009).

34. M.L. Crawford and G. Koepke, Design, Evaluation and Use of a Reverberation Chamber for Performing Electromagnetic Susceptibility/Vulnerability Measurement: Technical Note 1092. (National Institute of Standards and Technology, Gaithersburg, Maryland USA, 1999). https://nvlpubs. nist.gov/nistpubs/Legacy/TN/nbstechnicalnote1092.pdf.

35. B. Zhang, Z. Yuan, and J. He, in 2012 Asia-Pacific Symposium on Electromagnetic Compatibility, pp. 769-772 (2012)

36. M. Chaluvadi, G. Vincentraj, and K.G. Thomas, in IEEE International Conference on Power, Control, Signals and Instrumentation Engineering (ICPCSI-2017), pp. 13521355 (2017).

37. S. Kennedy, M.R. Yuce, and J.M. Redoute, in 2015 IEEE Global Electromagnetic Compatibility Conference (GEMCCON), pp. 1-5 (2017).

38. J. Malack, IEEE Trans. Electromagn. Compat. 20, 346 (1978)

39. B. Deutschmann, G. Winkler, and R. Jungreithmair, in 2002 IEEE International Symposium on Electromagnetic Compatibility, pp. 407-412 (2002).

40. F. Fiori and F. Musolino, IEEE Trans. Instrum. Meas. 52, 839 (2003).

41. M.L. Crawford, IEEE Trans. Electromagn. Compat. 16, 189 (1974).

42. K. Ivanus and A. Baric, in 2014 37th International Convention on Information and Communication Technology, Electronics and Microelectronics (MIPRO), pp. 110-114 (2014).

43. Testing and Measurement Techniques Part 8: Power Frequency Magnetic Field Immunity Test, Document IEC 61000-4 (2009).

44. Testing and Measurement Techniques Part 9: Pulse Magnetic Field Immunity Test, Document IEC 61000-4 (2001)

45. Testing and Measurement Techniques Part 10: Damped Oscillatory Magnetic Field Immunity Test, Document IEC 61000-4 (2001).

46. Y. Yang, Z. Song, L. Jiang, B. Rao, and M. Zhang, IEEE Trans. Ind. Electron. (2018). https://doi.org/10.1109/TIE.2 018.2807420

47. R.D. Leo and V.M. Primiani, in 2005 IEEE Instrumentationand Measurement Technology Conference Proceedings, pp. 337-341 (2005).

48. A.M. Silaghi, A.D. Sabata, F. Alexa, A. Buta, and S. Baderca, in 2016 12th IEEE International Symposium on Electronics and Telecommunications (ISETC), pp. 1-4 (2016).

49. V. Rodriguez, in 2014 International Symposium on Electromagnetic Compatibility, Tokyo, pp. 681-684 (2014).

50. J.R. Regue, M. Ribo, and J.M. Garrell, in 2001 IEEE EMC International Symposium. Symposium Record. International Symposium on Electromagnetic Compatibility (Cat. No.01CH37161), pp. 325-329 (2001).

51. M.A. Salhi, S. Cakr, M. Cinar, B. Tektas, and M. Cetintas, in 2016 International Symposium on Electromagnetic Compatibility - EMC EUROPE, pp. 25-256 (2016).

52. Testing and Measurement Techniques Part 3: Radiated, radio-frequency, electromagnetic field immunity test, Document IEC 61000-4 (2006).

53. K. Armstrong, in 2009 IEEE International Symposium on Electromagnetic Compatibility, pp. 30-35 (2009).

54. C.K. Tang, K.H. Chan, L.C. Fung, and S.W. Leung, IEEE Trans. Electromagn. Compat. 51, 659 (2009). 
55. S. Valavan, Understanding Electromagnetic Compliance Tests in Digital Isolators (Texas Instruments, 2014). http:// www.ti.com/lit/wp/slyy064/slyy064.pdf.

56. S. Cakr, O. Sen, S. Acak, and M. Cetintas, in 2015 IEEE International Symposium on Electromagnetic Compatibility (EMC), pp. 1260-1265 (2015).

57. R. Heinrich and D. Dutschmann, in IEEE 2010 Asia-Pacific International Symposium on Electromagnetic Compatibility, pp. 990-993 (2010).

58. J. Li, Z. Gong, S. Jin, H. Tian, and S. Ma, in 2017 IEEE 5th International Symposium on Electromagnetic Compatibility (EMC-Beijing), pp. 1-3 (2017).

59. S. Cakr, O. Sen, S. Acak, M. Azpurua, F. Silva, and M. Cetintas, IEEE Electromagn Compat 5, 45 (2016).

60. M. Camp, H. Garbe, and D. Nitsch, in 2002 IEEE International Symposium on Electromagnetic Compatibility, pp. 87-92 (2002).

61. K.L. Kaiser, Electrostatic Discharge (Boca Raton: Taylor $\backslash \&$ Francis Group, 2006).

62. J.J. Liou and K. Iniewski, Electrostatic Discharge Protection: Advances and Applications (New York: CRC Press Taylor \\& Francis Group, 2016).

63. H. Urbancokova, J. Valouch, and S. Kovar, J. Eng. Sci. Technol. Rev. 9, 14 (2016).

64. K. Wang, D. Pommerenke, R. Chundru, T.V. Doren, J.L. Drewniak, and A. Shashindranath, IEEE Trans. Electromagn. Compat 45, 258 (2003).

65. I. Mori, O. Fujiwara, S. Ishigami, and Y. Yamanaka, IEEJ Trans. EIS 125, 1798 (2005).

66. System-Level ESD Protection Guide. (Texas Instruments, 2018). http://www.ti.com/lit/sg/sszb130c/sszb130c.pdf (2018).

67. Testing and Measurement Techniques Part 2: Electrostatic Discharge Immunity Test, Document IEC 61000-4 (2008).

68. K. Nagai, D. Anzai, and J. Wang, in 2017 IEEE Conference on Antenna Measurements $\backslash \&$ Applications (CAMA), pp. 144-145 (2017).

69. T. Ishida, S. Nitta, F. Xiao, Y. Kami, and O. Fujiwara, in 2015 IEEE International Symposium on Electromagnetic Compatibility (EMC), pp. 839-842 (2015).

70. P.S. Katsivelis, I.F. Gonos, and I.A. Stathopulos, J. Electrostat. 77, 182 (2015).

71. T. Yoshida, in 2016 Asia-Pacific International Symposium on Electromagnetic Compatibility (APEMC), pp. 445-447 (2016).

72. M. Kohani, A. Bhandare, L. Guan, D. Pommerenke, and M.G. Pecht, IEEE Trans. Electromagn. Compat. 60, 1304 (2018).

73. J. Zhou, K. Ghosh, S. Xiang, X. Yan, A. Hosseinbeig, J. Lee, and D. Pommerenke, IEEE Trans. Electromagn. Compat. 60, 1313 (2018).

74. J. Park, J. Lee, C. Jo, B. Seol, and J. Kim, in $201840 t h$ Electrical Overstress/Electrostatic Discharge Symposium (EOS / ESD), pp. 1-6 (2018).

75. J. Koo, L. Han, S. Herrin, R. Moseley, R. Carlton, D.G. Beetner, and D. Pommerenke, IEEE Trans. Electromagn. Compat 51, 611 (2009).

76. Z. Zhou and Q. Jiang, in 2002 3rd International Symposium on Electromagnetic Compatibility, pp. 718-72 (2002).

77. Testing and Measurement Techniques Part 4: Testing and measurement techniques-Electrical fast transient/burst immunity test, Document IEC 61000-4, (2012).

78. B. Xiao, H. Yu, J. Wan, L. Jifang, in 2017 IEEE 5th International Symposium on Electromagnetic Compatibility (EMC-Beijing), pp. 1-4 (2017).

79. T. Williams, EMC for Product Designers, 5th ed. (London: Newnes, 2016), pp. 215-217.

80. M. Fontana and T.H. Hubing, IEEE Trans. Electromagn. Compat. 57, 188 (2015).

81. K. Taniguchi, M. Nagata, A. Tsukioka, D. Fujimoto, N. Miura, T. Egami, R. Akimoto, K. Niinomi, T. Komatsu, Y Fukuba, and A. Tomishima, in 2017 11th International
Workshop on the Electromagnetic Compatibility of Integrated Circuits (EMCCompo), pp. 59-63 (2017).

82. S. Matsushima, T. Matsushima, T. Hisakado, and O. Wada, IEEE Electromagn. Compat. 7, 46 (2018).

83. D.H. Pohren, A.S. Roque, T.I. Kranz, E.P.P. Freitas, and C.E. Pereira, IEEE Trans. Ind. Electron. (2019). https://doi. org/10.1109/TIE.2019.2901639.

84. J. Wu, B. Li, W. Zhu, H. Wang, and L. Zheng, Microelectron. Reliab. 76-77, 708 (2017).

85. D. Zhang, T. Hubing, A. Ritter, and C. Nies, IEEE Trans. Compon. Packag. Manuf. Technol. 6, 553 (2016).

86. S.B. Smith and R.B. Standler, IEEE Trans. Power Del. 7 , 1275 (1992).

87. C.F.M. Carobbi, A. Bonci, M. Stellini, and M. Borsero, IEEE Trans. Instrum. Meas. 62, 1840 (2013).

88. E. Tas, F. Pythoud, and B. Muehlemann, in 2018 International Symposium on Electromagnetic Compatibility (EMC EUROPE), pp. 482-487 (2018).

89. Testing and Measurement Techniques Part 5: Part 4-5: Testing and measurement techniques Surge immunity test, Document IEC 61000-4 (2005).

90. D.W. Harberts, in 2016 International Symposium on Electromagnetic Compatibility-EMC EUROPE, pp. 894897 (2016).

91. Testing and Measurement Techniques Part 5: Part 4-5: Testing and measurement techniques Voltage dips, short interruptions and voltage variations immunity tests, Document IEC 61000-4 (2017).

92. B. Renders, W.R. Ryckaert, K. De Gusseme, K. Stockman, and L. Vandevelde, Renew. Energy 33, 1011 (2008).

93. J.G. Nielsen and F. Blaabjerg, Trans. Ind. Appl. 41, 1272 (2005).

94. S. Sankaran, K. Deshmukh, M.B. Ahamed, and S.K. Khadheer Pasha, Compos. Part A 114, 49 (2018).

95. A. Tamburrano, D. Desideri, A. Maschio, and M.S. Sarto, IEEE Trans. Electromagn. Compat. 56, 1386 (2014).

96. P.F. Wilson, M.T. Ma, and J.W. Adams, IEEE Trans. Electromagn. Compat. 30, 239 (1988)

97. M.S. Sarto and A. Tamburrano, IEEE Trans. Electromagn. Compat. 48, 331 (2006).

98. P.F. Wilson, M.T. Ma, and J.W. Adams, IEEE Trans, Electromagn. Compat. 30, 251 (1988).

99. A. Nishikata, R. Saito, and Y. Yamanaka, in Symposium Record of 2004, pp. 609-612 (2004).

100. M. Rudd, T.C. Baum, and K. Ghorbani, IEEE Trans. Instrum. Meas. (2019). https://doi.org/10.1109/TIM.2019.289 5930 .

101. J. Carlsson, K. Karlsson, and A. Johansson, in International Symposium on Electromagnetic Compatibility-EMC EUROPE, pp. 17-21 (2012).

102. C.L. Holloway, D.A. Hill, J. Ladbury, G. Koepke, and R. Garzia, IEEE Trans. Electromagn. Compat. 35, 350 (2003).

103. V. Safarova, M. Tunak, M. Truhlar, and J. Militky, Text. Res. J. 86, 44 (2015).

104. S. Geetha, K.K.S. Kumar, C.R.K. Rao, M. Vijayan, and D.C. Trivedi, J. Appl. Polym. Sci. 112, 2073 (2009).

105. N. Dvurechenskaya, P.R. Bajurko, R.J. Zieliski, and Y. Yashchyshyn, Metrol. Meas. Syst. 20, 217 (2013).

106. I. Araz, Turk. J. Electr. Eng. Comput. Sci. 26, 2996 (2018).

107. P. Saini and M. Arora, Microwave Absorption and EMI Shielding Behavior of Nanocomposites Based on Intrinsically Conducting Polymers, Graphene and Carbon Nanotubes (InTECH, 2012). https://doi.org/10.5772/48779(2012).

108. X.C. Tong, Advanced Material and Design for Electromagnetic Interference Shielding (Boca Raton: CRC Press, 2009).

109. M.T. Sebastian, R. Ubic, and H. Jantunen, Microwave Materials and Applications (New York: Wiley, 2017).

110. S.A. Schelkunoff, Electromagnetic Waves (Princeton, 1943).

111. S. Celozzi, R. Araneo, and G. Lovat, Electromagnetic Shielding (New York: Wiley, 2008).

112. J.D. Kraus, Electromagnetics (New York: McGraw-Hill, 1992). 
113. F.P. Miller, A.F. Vandome, and J. McBrewster, Faraday Cage (VDM Publishing, 2009).

114. V.K. Kanth and S. Raghavan, IJEL (2018). https://doi.org/ 10.1080/21681724.2018.1545926.

115. S. Stefanou, J.S. Hamel, P. Baine, M. Bain, B.M. Armstrong, H.S. Gamble, M. Kraft, and H.A. Kemhadjian, IEEE Trans. Electron Devices 51, 486 (2004).

116. S.J. Chapman, D.P. Hewett, and L.N. Trefethen, SIAM Rev. 57, 398 (2015).

117. S. Kumar, R. Bhooshan, S. Varshney, C. Verma, and L. Gideon, in 2015 IEEE 17th Electronics Packaging and Technology Conference (EPTC), pp. 1-3 (2015).

118. J.R. Solin, IEEE Trans. Electromagn. Compat. 59, 529 (2017).

119. J.H. Wu, J. Scholvin, J.A. del Alamo, and K.A. Jenkins, IEEE Microw. Wireless Compon. Lett. 11, 410 (2001).

120. D. Moongilan and E. Mitchell, in 2008 IEEE International Symposium on Electromagnetic Compatibility, pp. 1-6 (2008).

121. T. Claeys, J. Catrysse, D. Pissoort, and Y. Arien, in 2018 International Symposium on Electromagnetic Compatibility (EMC EUROPE), pp. 725-729 (2018).

122. A.K. Singh, M.P. Abegaonkar, S.K. Koul, in 2017 IEEE MTT-S International Microwave and RF Conference (IM$a R C)$, pp. 243-246 (2017).

123. G. Li, L. Sheng, L. Yu, K. An, W. Ren, and X. Zhao, Mater. Sci. Eng. B 193, 153 (2015).

124. M.M. Tirkey and N. Gupta, Electromagn. Compat. 8, 59 (2019).

125. N.N. Ali, R.A.B. Al-Marjeh, Y. Atassi, A. Salloum, A. Malki, and M. Jafarian, J. Magn. Magn. Mater. 453, 53 (2018).

126. K.S.L. Al-badri, JKSUS (2018). https://doi.org/10.1016/j.jk sus.2018.07.013.

127. A. Emplit, F.F. Tao, C. Bailly, and I. Huynen, in 2013 European Microwave Conference, pp. 778-781 (2013).

128. M. Jafarian, S.S.S. Afghahi, Y. Atassi, and M. Salehi, J. Magn. Magn. Mater. (2018). https://doi.org/10.1016/j.jmm m.2018.09.047.

129. Y. Yang and M.C. Gupta, Nano Lett. 5, 2131 (2005).

130. J. Ma, M. Zhan, and K. Wang, ACS Appl. Mater. Interfaces (2014). https://doi.org/10.1021/am5067095.

131. T. Beeharry, R. Yahiaoui, K. Selemani, and H.H. Ouslimani, Sci. Rep. 8, 382 (2018).

132. I.W. Nam and H.K. Lee, Constr. Build. Mater. 115, 651 (2016).

133. D. Micheli, A. Vricella, R. Pastore, A. Delfini, R.B. Morles, M. Marchetti, F. Santoni, L. Bastianelli, F. Moglie, V.M. Primiani, V. Corinaldesi, A. Mazzoli, and J. Donnini, Constr. Build. Mater. 131, 267 (2017).

134. M. Ozturk, O. Akgol, U.K. Sevim, M. Karaaslan, M. Demirci, and E. Unal, Constr. Build. Mater. 165, 58 (2018).

135. D.P. Schmitz, T.I. Silva, S.D.A.S. Ramoa, G.M.O. Barra, A. Pegoretti, and B.G. Soares, J. Appl. Polym. Sci. (2018). https://doi.org/10.1002/app.46546.

136. R. Li, H. Lin, P. Lan, J. Gao, Y. Huang, Y. Wen, and W. Yang, Polymers (2018). https://doi.org/10.3390/poly $\mathrm{m} 10121319$.

137. M.H. Al-Saleh, Synth. Met. 217, 322 (2016).

138. N. Abdelal, J. Ind. Text. (2018). https://doi.org/10.1177/15 28083718798632

139. Y. Jia, K. Li, L. Xue, J. Ren, S. Zhang, and H. Li, Carbon 111, 299 (2017).

140. Y. Wang, F. Gu, L. Ni, K. Liang, K. Marcus, S. Liu, F. Yang, J. Chen, and Z. Feng, Nanoscale 9, 18318 (2017).

141. H. Zhao, L. Hou, S. Bi, and Y. Lu, ACS Appl. Mater. Interfaces 9, 33059 (2017).

142. R. Rohini and S. Bose, Compos. Part B 161, 578 (2019).

143. C. Xianhua, G. Yuxiao, and P. Fusheng, Rare Met. Mater. Eng. 45, 13 (2016)

144. D. Xing, L. Lu, K.S. Teh, Z. Wan, Y. Xie, and Y. Tang, Carbon 132, 32 (2018).

145. S. Mishra, P. Katti, S. Kumar, and S. Bose, Chem. Eng. Sci. 357, 384 (2018).

146. Y. Hu, H. Zhang, F. Li, X. Cheng, and T. Chen, Polym. Test. 29,609 (2010).
147. R. Kumar, H.K. Choudhary, A.V. Anupama, A.V. Menon, S.P. Pawar, S. Bosec, and B. Sahoo, New J. Chem. (2019). https://doi.org/10.1039/c9nj00639g.

148. X. Yu, Z. Shen, and C. Cai, Vacuum 83, 1438 (2009).

149. D. Kim, Y. Kim, and J.W. Kim, Mater. Des. 89, 703 (2016).

150. N.N. Lu, X.J. Wang, L.L. Meng, C. Ding, W.Q. Liu, H.L. Shi, X.S. Hu, and K. Wu, J. Alloys Compd. 650, 871 (2015).

151. G.H. Kang and S.H. Kim, Appl. Surf. Sci. 380, 114 (2016).

152. J. Koprowska, J. Ziaja, and J. Janukiewicz, in 2008 International Symposium on Electromagnetic Compatibility-EMC Europe, pp. 1-4 (2008).

153. A. Hulle and A. Powar, J. Text. Sci. Eng. (2018). https://doi. org/10.4172/2165-8064.1000347.

154. M. Tian, M. Du, L. Qu, S. Chen, S. Zhuabc, and G. Han, RSC Adv. 7, 42641 (2017).

155. Y. Tan, J. Li, Y. Gao, J. Li, S. Guo, and M. Wang, Appl. Surf. Sci. 458, 236 (2018).

156. L. Geng, P. Zhu, Y. Wei, R. Guo, C. Xiang, C. Cui, and Y. Li, Cellulose 26, 2833 (2019).

157. J.W. Ott, Electromagnetic Compatibility Engineering (New York: Wiley, 2011), pp. 464-467.

158. R.L. Ozenbaugh and T.M. Pullen, EMI Filter Design, 2nd ed. (Boca Raton: CRC Press, 2000).

159. S. Wang, F.C. Lee, and W.G. Odendaal, IEEE Trans. Power Electron. 20, 974 (2005).

160. H.M. Schlicke, IEEE Trans. Electromagn. Compat. 6, 47 (1964).

161. F.O. Johnson, in 1969 IEEE Electromagnetic Compatibility Symposium Record, pp. 336-341 (1969).

162. D.M. Mitchell, IEEE Trans. Electromagn. Compat. 20, 457 (1978).

163. C.R. Paul and K.B. Hardin, IEEE Trans. Electromagn. Compat. 30, 553 (1988).

164. F.Y. Shih, D.Y. Chen, Y.P. Wu, and Y.T. Chen, IEEE Trans. Power Electron. 11, 170 (1996).

165. H.F. Chen, C.Y. Yeh, and K.H. Lin, IEEE Trans. Power Electron. 24, 2867 (2009).

166. S. Boonruang, V. Tarateeraseth, in 2018 15th International Conference on Electrical Engineering/Electronics, Computer, Telecommunications and Information Technology (ECTI-CON), pp. 756-759 (2018).

167. L. Nan and Y. Yugang, in 2006 CES/IEEE 5th International Power Electronics and Motion Control Conference, pp. 1-5 (2006).

168. Y. Maillet, R. Lai, S. Wang, F. Wang, R. Burgos, and D. Boroyevich, IEEE Trans. Power Electron. 25, 1163 (2010).

169. D. Shin, S. Kim, G. Jeong, J. Park, J. Park, K.J. Han, and J. Kim, IEEE Trans. Electromagn. Compat. 57, 660 (2015).

170. D. Hamza, M. Sawan, and P.K. Jain, IET Power Electron. 4, 776 (2011).

171. R. Goswami, S. Wang, E. Solodovnik, and K. Karimi, IEEE J. Emerg. Sel. Topics Power Electron 7, 576 (2019).

172. N. Valentine, M.H. Azarian, and M. Pecht, Microelectron. Reliab. 92, 123 (2019).

173. S.H. Ryu, S.B. Park, and S.W. Kim, in 2015 IEEE International Conference on Consumer Electronics (ICCE), pp. 610-611 (2015).

174. A. Bhargava, D. Pommerenke, K.W. Kam, F. Centola, and C.W. Lam, IEEE Trans. Electromagn. Compat. 53, 806 (2011).

175. C.H. Lee, C.Y. Yao, H.C. Li, D.B. Lin, and H.P. Lin, in 2017 Progress in Electromagnetics Research Symposium-Fall (PIERS-FALL), pp. 1568-1571 (2017).

176. K.B. Hardin, J.T. Fessler, and D.R. Bush, in Proceedings of IEEE Symposium on Electromagnetic Compatibility, pp. 227-231 (1994).

177. P.M. Vidya and S. Sudha, in 2016 IEEE Technological Innovations in ICT for Agriculture and Rural Development (TIAR), pp. 213-217 (2016).

Publisher's Note Springer Nature remains neutral with regard to jurisdictional claims in published maps and institutional affiliations. 